\title{
Harnessing Infrared Photons for Photoelectrochemical Hydrogen Generation. A PbS Quantum Dot Based "Quasi- Artificial Leaf"
}

\begin{tabular}{|r|l|}
\hline Journal: & The Journal of Physical Chemistry Letters \\
\hline Manuscript ID: & jz-2012-01890m.R1 \\
\hline Manuscript Type: & Letter \\
\hline Date Submitted by the Author: & n/a \\
\hline Complete List of Authors: & $\begin{array}{l}\text { Trevisan, Roberto; Universitat Jaume I de Castello, Physics } \\
\text { Rodenas, Pau; Universitat Jaume I de Castello, Physics } \\
\text { Gonzalez-Pedro, Victoria; Universitat Jaume I, Dept. de Física } \\
\text { Sima, Cornelia; National Institute of Lasers, Plasma and Radiation Physics, }, \\
\text {; University of Bucharest, Faculty of Physics } \\
\text { Sánchez, Rafael; Universidad Autonoma de Barcelona, Chemistry } \\
\text { Barea, Eva; Universitat Jaume I, Physics } \\
\text { Mora-Sero, Ivan; Universitat Jaume I, Physics } \\
\text { Fabregat-Santiago, Francisco; Universitat Jaume I, Physics } \\
\text { Gimenez, Sixto; University Jaume I de Castello, Physics }\end{array}$ \\
\hline \multicolumn{2}{|l}{} \\
\hline
\end{tabular}

SCHOLARONE ${ }^{\text {M }}$

Manuscripts 


\title{
Harnessing Infrared Photons for Photoelectrochemical Hydrogen Generation. A PbS
} Quantum Dot Based “Quasi-Artificial Leaf”

Roberto Trevisán, ${ }^{1}$ Pau Ródenas, ${ }^{1}$ Victoria González-Pedro, ${ }^{1}$ Cornelia Sima, ${ }^{1,2,3}$ Rafael Sánchez, ${ }^{1}$ Eva M. Barea, ${ }^{1}$ Iván Mora-Seró, ${ }^{1,}{ }^{*}$ Francisco Fabregat-Santiago, ${ }^{1}$ Sixto Giménez ${ }^{1, *}$

${ }^{1}$ Photovoltaics and Optoelectronic Devices Group, Departament de Física, Universitat Jaume I, 12071 Castelló, Spain

2 National Institute of Lasers, Plasma and Radiation Physics, Atomistilor 409 street, P.O. Box MG 36 Bucharest-Magurele, 077125, Romania

${ }^{3}$ University of Bucharest, Faculty of Physics, Atomistilor 405 street, MG-11 BucharestMagurele, 077125, Romania

*Email: sero@uji.es, sjulia@uji.es

\begin{abstract}
Hydrogen generation by using quantum dot based heterostructures has emerged as a promising strategy to develop artificial photosynthesis devices. In the present study, we sensitize mesoporous $\mathrm{TiO}_{2}$ electrodes with in-situ deposited $\mathrm{PbS} / \mathrm{CdS}$ quantum dots (QDs), aiming at harvesting light in both the visible and the near infrared for hydrogen generation. This heterostructure exhibits a remarkable photocurrent of $6 \mathrm{~mA} \cdot \mathrm{cm}^{-2}$ leading to $60 \mathrm{ml} \cdot \mathrm{cm}^{-2} \cdot$ day $^{-1}$ hydrogen generation. Most importantly, confirmation of the contribution of infrared photons to $\mathrm{H}_{2}$ generation was provided by the incident-photon-to-current-efficiency (IPCE), and the integrated current was in excellent agreement with that obtained through cyclic voltammetry. The main electronic processes (accumulation, transport and recombination) were identified by impedance spectroscopy, which appears as a simple and reliable methodology to evaluate the limiting factors of these photoelectrodes. Based on this $\mathrm{TiO}_{2} / \mathrm{PbS} / \mathrm{CdS}$ heterostructrure, a "quasiartificial leaf" has been developed, which has proven to produce hydrogen under simulated solar illumination at $(4.30 \pm 0.25) \mathrm{ml} \cdot \mathrm{cm}^{-2} \cdot \mathrm{day}^{-1}$.
\end{abstract}




\section{Table of Contents (TOC)}

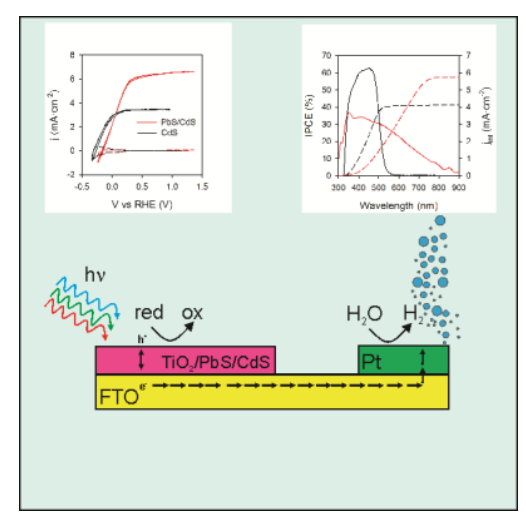

Here we present a Quantum Dot based “quasi-artificial leaf”, based on a $\mathrm{TiO}_{2} / \mathrm{PbS} / \mathrm{CdS}$ heterostructured nanocomposite electrode, harnessing infrared photons for solar $\mathrm{H}_{2}$ generation. The device has demonstrated to produce $4.30 \mathrm{ml} \cdot \mathrm{cm}^{-2} \cdot$ day $^{-1} \mathrm{H}_{2}$, confirmed through labeling experiments. The photoelectrochemical characterization of the material also provided an accurate description of the transport and accumulation of charge carriers in the device.

Keywords: Hydrogen generation, quantum dots, lead sulfide, cadmium sulfide, titanium dioxide, impedance spectroscopy 
The provision of clean and renewable energy to satisfy the increasing human demands in the XXI century is one of the key challenges to sustain the present global social and economical model. ${ }^{1,2}$ Sunlight offers a huge potentiality for global supply of renewable energy, provided that this energy can be stored for its use upon demand. In this context, photoelectrochemical hydrogen generation by water splitting with semiconductor materials constitutes the simplest conversion scheme, since $\mathrm{H}_{2}$ can be produced with the only input of water and sunlight and $\mathrm{H}_{2}$ combustion in hydrogen fuel cells leads to electricity with water as the only byproduct, resulting in a $\mathrm{CO}_{2}$ neutral process. ${ }^{2-4}$ The key challenge of this approach relies on whether this goal can be met in a cost-effective way on the terawatt scale. ${ }^{2}$

Since the seminal report of Fujishima and Honda in 1972 demonstrating the photocatalysis of $\mathrm{TiO}_{2}$ for $\mathrm{H}_{2}$ generation, ${ }^{5}$ a dynamic search for the optimum semiconductor material and device configuration was launched, but crystallization of this research activity into a well developed technology has not been achieved yet, mainly because none of the explored materials simultaneously meet the different needed requirements for adequate device operation; i.e. a bandgap comprised between 1.9-2.2 eV, conduction and valence band edges straddling the water oxidation and hydrogen reduction potentials, good conductivity and low cost. ${ }^{2,4}$ The novel developments in the fields of nanoscience and catalysis ${ }^{6}$ have provided key elements and concepts to rationalize the search for promising materials and device architectures. Orthogonalization of light absorption and carrier diffusion, ${ }^{7-9}$, quantum confinement, ${ }^{10}$ band energetics engineering ${ }^{11}$ and plasmonics ${ }^{12,13}$ appear as fascinating strategies, which can be exploited to enhance the efficiencies of photoelectrochemical hydrogen generation devices. Sensitization of wide oxide semiconductors like $\mathrm{ZnO}$ or $\mathrm{TiO}_{2}$ by chalcogenide quantum dots also provides a convenient heterostructured platform for photoelectrochemical $\mathrm{H}_{2}$ generation. Indeed, this approach, has showed promising results: Hensel et al. showed the synergistic effect of $\mathrm{N}$ doping of $\mathrm{TiO}_{2}$ nanowires and CdSe sensitization leading to photocurrents close to $3 \mathrm{~mA} \cdot \mathrm{cm}^{-2} \cdot{ }^{14}$ Combining $\mathrm{ZnO}$ nanowires with CdTe quantum dots, Chen et al. obtained photocurrents close to $2 \mathrm{~mA} \cdot \mathrm{cm}^{-2}$ using a non-sacrificial hole scavenger. ${ }^{15}$ Hierarchical $\mathrm{ZnO} / \mathrm{WO}_{\mathrm{x}}$ nanowires cosensitized with $\mathrm{CdSe} / \mathrm{CdS}$ led to promising photocurrents close to $12 \mathrm{~mA} \cdot \mathrm{cm}^{-2}$ and light-tochemical conversion efficiencies of $6 \% .{ }^{16}$ More recently, Luo et al. have highlighted the 
importance of the controlled deposition of the light absorbing semiconductor (CdSe) on inverse opals of $\mathrm{TiO}_{2}$, achieving photocurrents of $15.7 \mathrm{~mA} \cdot \mathrm{cm}^{-2}$ for hydrogen generation. ${ }^{17}$

On the other hand, an optimal exploitation of the solar spectrum for photoelectrochemical energy conversion must entail the use of narrow bandgap semiconductors, like $\mathrm{PbS}$, in order to harness infrared photons for photoelectrochemical conversion. Tada et al. ${ }^{18}$ have reported a solar-tohydrogen conversion efficiency of $1.15 \%$ and a hydrogen production rate of $5.2 \mathrm{ml} \cdot \mathrm{h}^{-1}$ employing a heterostructure based on mesoporous $\mathrm{TiO}_{2}$ decorated with colloidal $\mathrm{PbS}$ quantum dots (under the application of bias). In the present study, we have developed a hybrid architecture based on $\mathrm{TiO}_{2}$ mesoporous frame functionalized with in-situ grown $\mathrm{PbS} / \mathrm{CdS}$ QDs, targeting at an unassisted photoelectrochemical hydrogen generation device. The ultimate goal is achieving a system able to convert visible, but also infrared photons into $\mathrm{H}_{2}$. Great benefit can be derived from the collection of IR photons since they represent practically $50 \%$ of the solar spectrum photons.

Colloidal $\mathrm{PbS}$ quantum dots have demonstrated to harness the infrared photons towards efficient solar hydrogen production. ${ }^{18}$ We have incorporated in-situ grown PbS quantum dots onto a mesoporous $\mathrm{TiO}_{2}$ structure together with $\mathrm{CdS}$ quantum dots to both enhance the visible response (see Supporting Information, Figure SI1) and stabilize the whole material. ${ }^{19}$ The microscopic inspection of the material by SEM showed the mesoporous $\mathrm{TiO}_{2}$ structure but did not reveal any morphological details of the $\mathrm{PbS} / \mathrm{CdS}$ sensitizers (Supporting information, Figure SI2). The presence of $\mathrm{PbS}$ QDs was confirmed through XRD spectra carried out on $\mathrm{TiO}_{2} / \mathrm{PbS}$ structures (Supporting information, Figure SI3). High resolution TEM images (Supporting information, Figure SI4) reveal that both $\mathrm{PbS}$ and $\mathrm{CdS}$ appear as scattered nanoparticles (diameter below 10 $\mathrm{nm}$ ) onto the mesoporous $\mathrm{TiO}_{2}$ network, and covered by a $\mathrm{ZnS}$ layer.

The photoelectrochemical behavior of $\mathrm{TiO}_{2} / \mathrm{PbS} / \mathrm{CdS}$ heterostructures in an aqueous solution containing 0.25 $\mathrm{M} \mathrm{Na}_{2} \mathrm{~S}$ and $0.35 \mathrm{M} \mathrm{Na}_{2} \mathrm{SO}_{3}$ as sacrificial hole scavenger in the dark and under illumination is showed in Figure 1a. As a reference, results for $\mathrm{TiO}_{2} / \mathrm{CdS}$ are also included. It is clear that higher photocurrents are obtained when $\mathrm{PbS}$ is included in the heterostructures. At $0 \mathrm{~V}$ vs RHE, a photocurrent of $2 \mathrm{~mA} \cdot \mathrm{cm}^{-2}$ is obtained for both systems. Saturation of the 
photocurrent takes place at approximately $0.4 \mathrm{~V}$ vs RHE, with $6 \mathrm{~mA} \cdot \mathrm{cm}^{-2}$ for $\mathrm{TiO}_{2} / \mathrm{PbS} / \mathrm{CdS}$ and $3.5 \mathrm{~mA} \cdot \mathrm{cm}^{-2}$ or $\mathrm{TiO}_{2} / \mathrm{CdS}$. This equals $60 \mathrm{~mL} \cdot \mathrm{cm}^{-2} \cdot \mathrm{day}^{-1}$ and $35 \mathrm{~mL} \cdot \mathrm{cm}^{-2} \cdot \mathrm{day}^{-1}$ hydrogen generation rate, respectively, assuming a faradaic efficiency unity. The observed positive photocurrents correspond to hole injection from the heterostructured $\mathrm{TiO}_{2} / \mathrm{QDs}$ photoanode into the solution. The difference between the anodic and cathodic branches of the dark cyclic voltammetry curve, at potentials below $0 \mathrm{~V}$ vs $\mathrm{RHE}$ (more visible for $\mathrm{TiO}_{2} / \mathrm{CdS}$ structure) is due to the chemical capacitance of $\mathrm{TiO}_{2}$, consistently with previous studies. ${ }^{20-22}$. Labeling experiments of the evolved gas at the Pt counterelectrode was collected in an inverted burette and analyzed. The results for $\mathrm{TiO}_{2} / \mathrm{PbS} / \mathrm{CdS}$ are showed Figure $1 \mathrm{~b}$ clearly indicating that the generated gas is hydrogen. Additionally, the stability of these photoelectrodes was tested by chronoamperometric measurements. The electrodes showed to be stable (no decrease of photocurrent during more than 1 hour, and the loss of performance detected was due to the depletion of the sacrificial agent in the solution (see Supporting Information, Figure SI5).

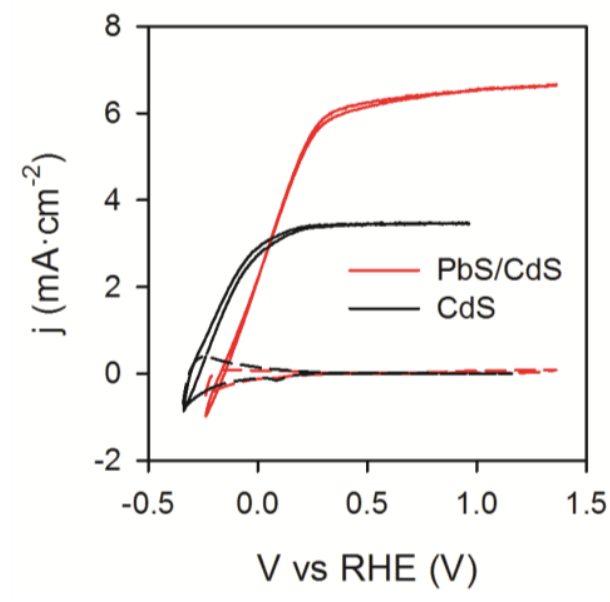

(a)

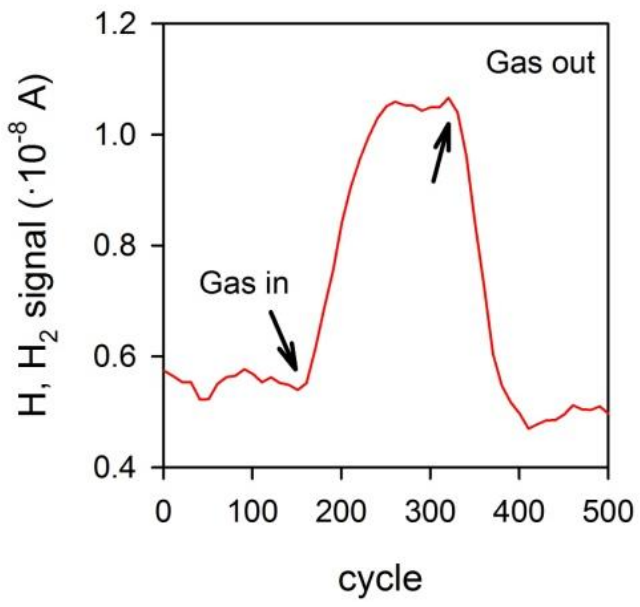

(b)

Figure 1.- (a) $\mathrm{j}-\mathrm{V}$ curves for the $\mathrm{TiO}_{2} / \mathrm{PbS} / \mathrm{CdS}$ heterostructure in the dark (dashed lines) and under illumination at $100 \mathrm{~mW} \cdot \mathrm{cm}^{-2}$ (solid lines) obtained by cyclic voltammetry in three electrode configuration, the results for $\mathrm{TiO}_{2} / \mathrm{CdS}$ are also included as a reference (b) Gas chromatography Mass Spectroscopy plot of the evolved gas for $\mathrm{TiO}_{2} / \mathrm{PbS} / \mathrm{CdS}$ heterostructure. The signal of $\mathrm{H}_{2}$ is clearly increased after gas is passed through the system.

The results obtained from the photoelectrochemical characterization showed in Figure 1a suggest that $\mathrm{TiO}_{2}, \mathrm{PbS}$ and $\mathrm{CdS}$ form a cascaded structure, and photogenerated electrons at both $\mathrm{CdS}$ and $\mathrm{PbS}$ can be collected at the contact, although further research is needed to unambiguously 
stablish this point. Figure 2 shows a proposed energy diagram, based on literature data, ${ }^{24,25}$ in which the different electronic processes and relevant electrochemical reactions are scheduled. Further quantification of the position of the energy levels of the conduction and valence band edges for QDs is out of the scope of the present study. Extensive discussion of the reaction mechanisms has been reported elsewhere. ${ }^{14,15,18,23,24}$ The presence of $\mathrm{Na}_{2} \mathrm{~S}$ and $\mathrm{Na}_{2} \mathrm{SO}_{3}$ hole scavengers in the electrolyte provides a fast shuttle for the photogenerated holes (reaction 1) avoiding photocorrosion, while electrons are driven through $\mathrm{TiO}_{2}$ toward the contact, and then to the catalytic cathode, where hydrogen generation takes place (reaction 2).

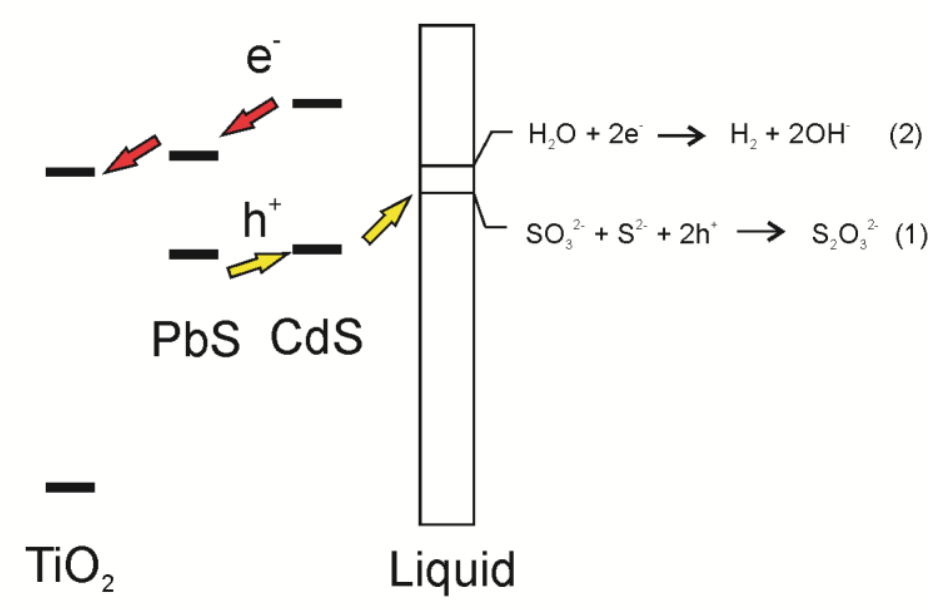

Figure 2. Energy diagram illustrating the oxidation at $\mathrm{PbS} / \mathrm{CdS}$ QDs-sensitized $\mathrm{TiO}_{2}$ particulate anodes. Energy levels were adapted from ${ }^{25,26}$. The arrows indicate the traffic of electrons and holes.

In order to gain further insight into the charge transfer mechanisms of $\mathrm{TiO}_{2} / \mathrm{PbS} / \mathrm{CdS}$ heterostructuctures, chopped light j-V curves were carried out. Figure 3a shows the superimposed chopped and constant light $\mathrm{j}-\mathrm{V}$ curves. The presence of current transients (spikes) in the chopped light curve provides direct evidence of the participation of surface states in the hole transfer process. Indeed, the presence of these transients has been attributed to the charging (trapping of holes) of surface states, or oxidizing surface species. ${ }^{27-29}$ The presence of surface states for $\mathrm{PbS}$ has been also recognized in the recombination process for quantum dot sensitized solar cells. ${ }^{19}$ In contrast, we have previously showed that when CdS/CdSe quantum dots are used 
as light absorbers, the hole collection efficiency is unity (spikes are not observed in the chopped light $\mathrm{j}$-V curves). ${ }^{30}$

The contribution of infrared photons to the higher photocurrent measured for $\mathrm{TiO}_{2} / \mathrm{PbS} / \mathrm{CdS}$ (and hence to the $\mathrm{H}_{2}$ generation) was assessed by measuring the incident-photon-to-current-efficiency (IPCE) action spectrum in a three electrode configuration, at $0.95 \mathrm{~V}$ vs RHE. The results for $\mathrm{TiO}_{2} / \mathrm{CdS}$ are also showed as a reference (see Figure $3 \mathrm{~b}$ ). The IPCE action spectrum for $\mathrm{TiO}_{2} / \mathrm{CdS}$ extends up to $550 \mathrm{~nm}$, while when $\mathrm{PbS}$ is included in the heterostructure, the wavelength range expands beyond $800 \mathrm{~nm}$, confirming the contribution of infrared photons to the photocurrent. Indeed, the IPCE action spectrum practically mimics the optical density, and the APCE (absorbed photon to current efficiency) values are practically identical to IPCE as showed in Supporting Information, Figure SI6, for $\mathrm{TiO}_{2} / \mathrm{PbS} / \mathrm{CdS}$. Integration of the IPCE spectrum with wavelength led to a total photocurrent of $5.7 \mathrm{~mA} \cdot \mathrm{cm}^{-2}$ and $4.1 \mathrm{~mA} \cdot \mathrm{cm}^{-2}$ for $\mathrm{TiO}_{2} / \mathrm{PbS} / \mathrm{CdS}$ and $\mathrm{TiO}_{2} / \mathrm{CdS}$, respectively (Figure $3 \mathrm{~b}$ ) in excellent agreement with the maximum photocurrent showed in Figure $1\left(6 \mathrm{~mA} \cdot \mathrm{cm}^{-2}\right.$ and $3.5 \mathrm{~mA} \cdot \mathrm{cm}^{-2}$, respectively).

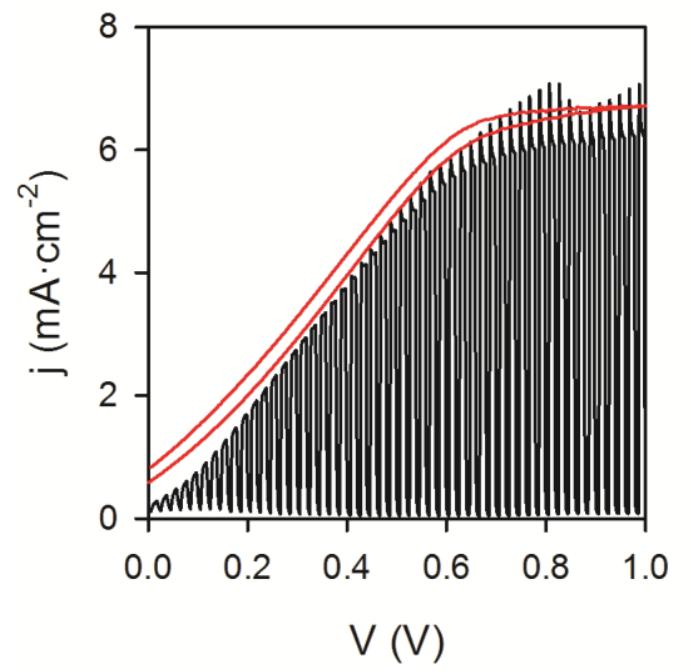

(a)

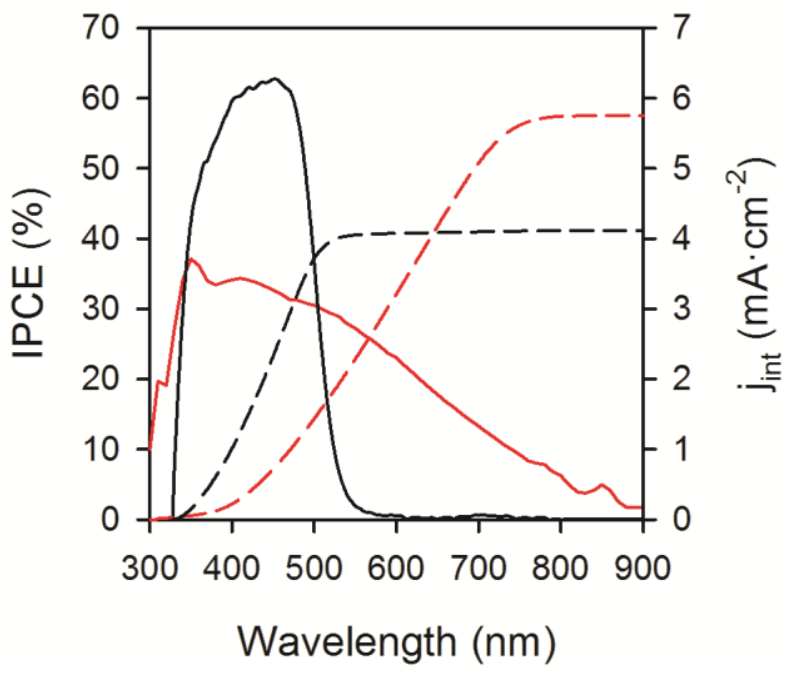

(b)

Figure 3.- (a) Chopped light (black) and constant (red) illumination $\mathrm{j}-\mathrm{V}$ curves in two electrode configuration of the $\mathrm{TiO}_{2} / \mathrm{PbS} / \mathrm{CdS}$ heterostructured photoanode. (b) IPCE (solid lines) and integrated current (dashed lines) for $\mathrm{T} \mathrm{TiO}_{2} / \mathrm{PbS} / \mathrm{CdS}$ (red) and a reference $\mathrm{TiO}_{2} / \mathrm{CdS}$ (black) photoelectrode at $0.95 \mathrm{~V}$ vs RHE. 
Further photoelectrochemical characterization of the heterostructured $\mathrm{TiO}_{2} / \mathrm{PbS} / \mathrm{CdS}$ photoanodes was carried out by impedance spectroscopy measurements in the dark and under illumination. A sound physical model was already developed for similar heterostructured materials, ${ }^{19,30-32}$ which is scheduled as supporting information, Figure SI7. Consequently, this model was directly applied to extract the chemical capacitance of $\mathrm{TiO}_{2}, \mathrm{C}_{\mu}$, the recombination resistance, $\mathrm{R}_{\mathrm{rec}}$ and the transport resistance, $\mathrm{R}_{\text {tr }}$ of the $\mathrm{TiO}_{2} / \mathrm{PbS} / \mathrm{CdS}$ architectures. $\mathrm{C}_{\mu}$ monitors the density of states (DOS) at the Fermi level, and provides the distribution of trap states below the conduction band of $\mathrm{TiO}_{2}, \mathrm{R}_{\mathrm{tr}}$ is directly proportional to the resistivity of $\mathrm{TiO}_{2}\left(\rho_{\mathrm{TiO} 2}\right)$ and $\mathrm{R}_{\mathrm{rec}}$ is inversely proportional to the recombination rate of electrons at the $\mathrm{TiO}_{2} /$ solution interface. $^{20,33,34}$ The exponential behavior of the transport resistance with voltage in the QD sensitized films follows identical exponential trend as compared to bare and dye sensitized $\mathrm{TiO}_{2}$, suggesting that electron transport occurs mainly through the $\mathrm{TiO}_{2}$ nanoparticles rather than through QDs. ${ }^{21}$ Furthermore, the transport resistance $\left(\mathrm{R}_{\mathrm{tr}}\right)$ for $\mathrm{TiO}_{2}$ is very similar in the dark and under illumination (Figure 4a). This is an expected result, since the conductivity of the $\mathrm{TiO}_{2}$ nanoparticles is determined by the electron density in the conduction band which, is controlled by the applied potential and not by illumination. The chemical capacitance (Figure 4b) shows the characteristic exponential dependence with potential, reflecting the trap state distribution below the conduction band of $\mathrm{TiO}_{2}$. This agrees well with the assumption that charge is accumulated and transported mainly through the $\mathrm{TiO}_{2}$. The behavior of $\mathrm{C}_{\mu}$ is very similar in the dark and under illumination conditions again, since it is determined by the position of the Fermi level which is governed by the applied bias. The small difference found at the intermediate states between dark and illumination conditions may be due to a capacitive contribution from the accumulation of charges in the QDs.

Finally, the recombination resistance, $R_{\text {rec }}$ is governing the photoelectrochemical behavior of the heterostructure, since the total resistance obtained by derivation of the $\mathrm{j}-\mathrm{V}$ curve, also including series resistances, practically mimics the $\mathrm{R}_{\text {rec }}$ values obtained by impedance spectroscopy both in the dark (Figure 4c) and under illumination (Figure 4d). Therefore, impedance spectroscopy appears as a very attractive experimental technique to monitor the main processes controlling the performance of these materials. 


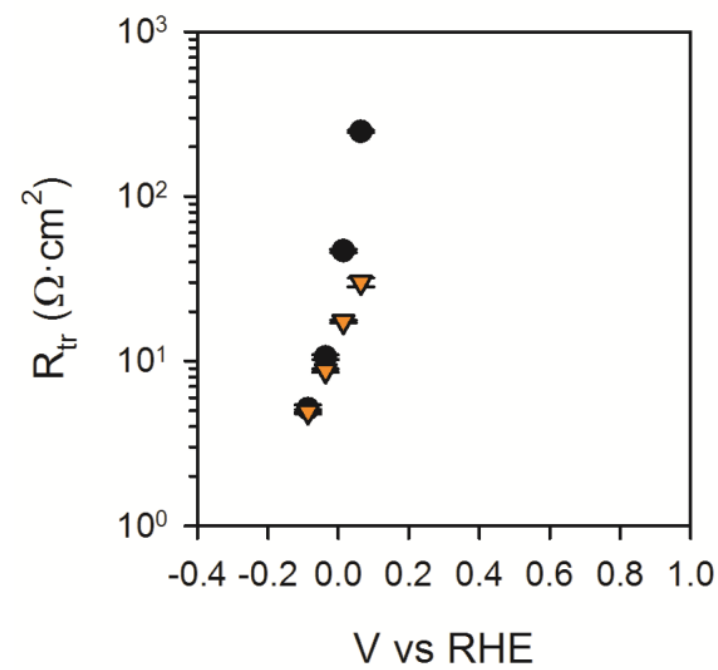

(a)

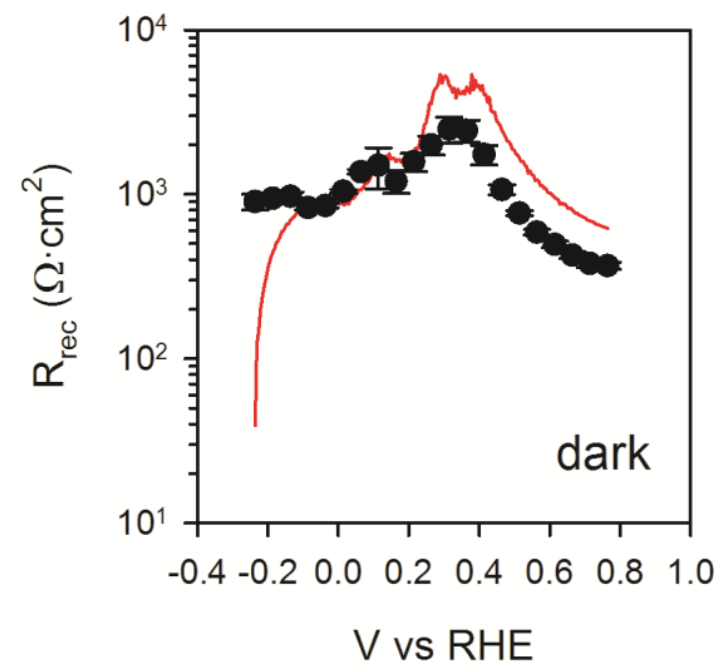

(c)

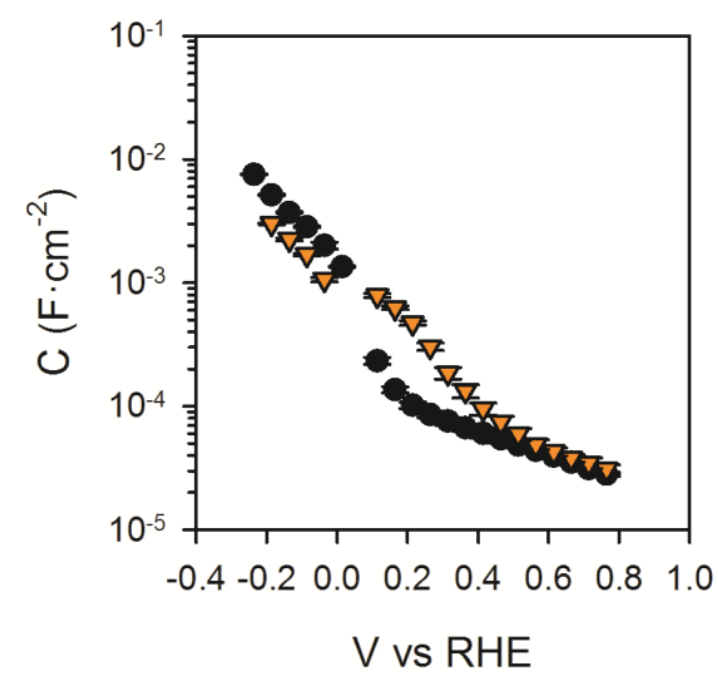

(b)

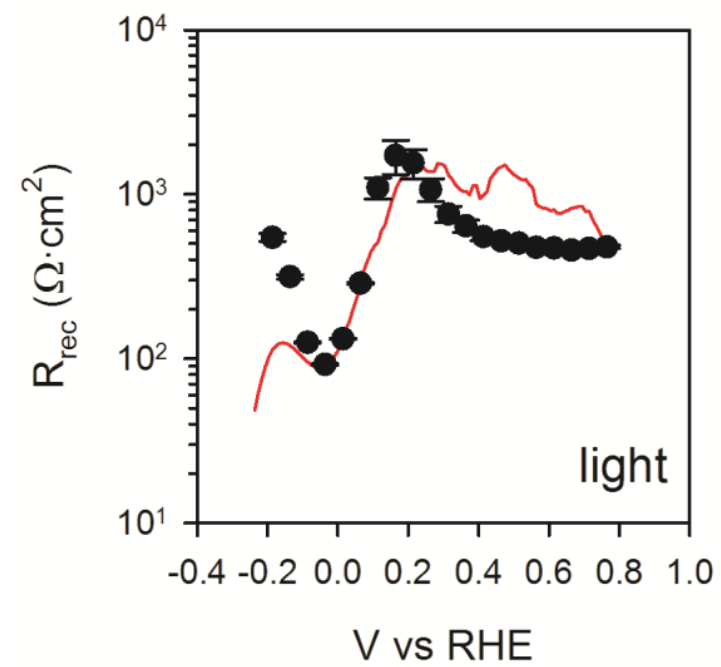

(d)

Figure 4.- Parameters extracted after fitting the impedance spectroscopy spectra of the heterostructured $\mathrm{TiO}_{2} / \mathrm{PbS} / \mathrm{CdS}$ photoanodes, using the model previously developed and showed as Supporting Information, Figure SI7. ${ }^{30-32}$ (a) Transport resistance, $\mathrm{R}_{\mathrm{tr}}$, (b) Chemical capacitance, $\mathrm{C}_{\mu}$, (c) recombination resistance, $\mathrm{R}_{\mathrm{rec}}$ as a function of potential both in the dark and (d) under illumination. The red lines in (c) and (d) represent the total resistance extracted from derivation of the $\mathrm{j}-\mathrm{V}$ curve, $R=\left(\frac{d j}{d V}\right)^{-1}$. Error bars assigned to the experimental points have been obtained from the fitting error. 
From all the above results, $\mathrm{TiO}_{2} / \mathrm{PbS} / \mathrm{CdS}$ photoanodes show promising capabilities to drive solar $\mathrm{H}_{2}$ generation. Consequently, we assembled a wireless device, resembling an artificial leaf ${ }^{35,36}$ integrating this heterostructure as scheduled in Figure 5(a). The device is immersed into the aqueous solution, and upon illumination, electro-hole pairs are photogenerated in the light absorber ( $\mathrm{PbS} / \mathrm{CdS} \mathrm{QDs})$. The holes are quickly injected in the solution driving the sacrificial oxidation of $\mathrm{SO}_{3}{ }^{2-}$. On the other hand, photogenerated electrons are transported through the $\mathrm{TiO}_{2}$ mesoporous structure toward the FTO substrate and then to the catalytic cathode, which is composed by a calcined chloroplatinic solution, where hydrogen can evolve. Hydrogen evolution is observed as showed in Figure 5(b) and Supporting Information, audiovisual material. The hydrogen generation rate was $0.18 \mathrm{ml}$ during 1 hour of measurement, which equals $(4.30 \pm 0.25)$ $\mathrm{ml} \cdot \mathrm{cm}^{-2} \cdot \mathrm{day}^{-1}$. It is important to highlight that at this stage, this device cannot be strictly termed "artificial leaf" since the use of a sacrificial agent is needed for operation. However, we believe that this "quasi-artificial leaf" constitutes a promising structure for future developments and different optimization strategies are under investigation in our lab to improve the device efficiency, stability and autonomy. Particularly, in order to achieve higher $\mathrm{H}_{2}$ generation rates, morphological optimization of the $\mathrm{TiO}_{2}$ structure is an important issue to be addressed, since it has been proven that structures with lower surface area lead to better performance of quantum dot sensitized solar cells based on these structures. ${ }^{37,38}$ Doping has also demonstrated to enhance $\mathrm{TiO}_{2}$ conductivity and minimize transport losses. ${ }^{14}$ Additionally, the presence of $\mathrm{PbS}$ enhances charge recombination, (the lower IPCE values in the range $350-550 \mathrm{~nm}$ when PbS is included in the structure is a good evidence) and efficient passivation strategies need to be developed as previously done with colloidal PbS QDs. ${ }^{39}$ 


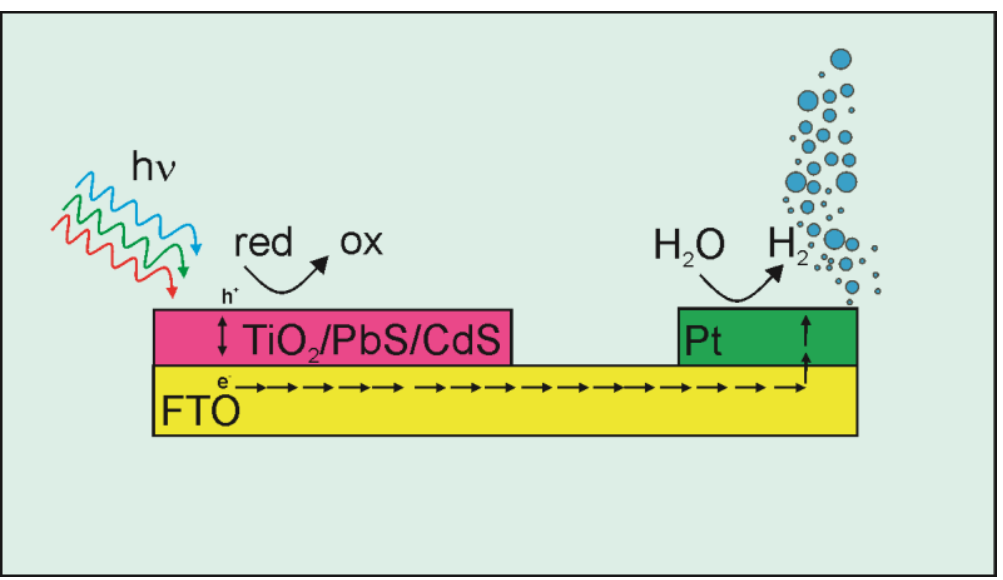

(a)

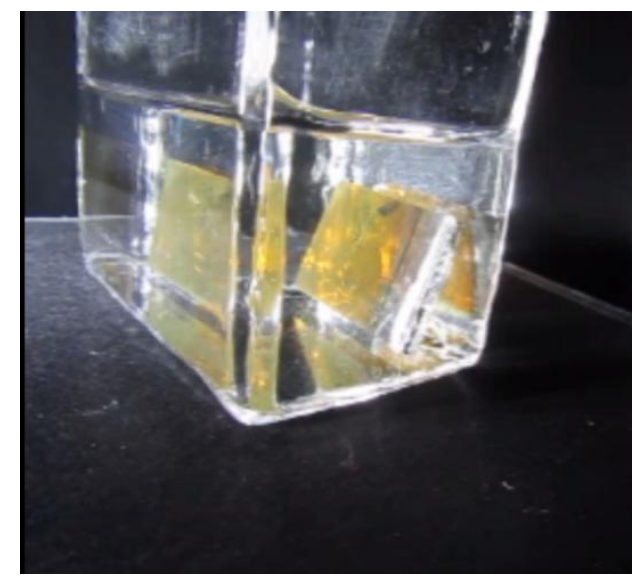

(b)

Figure 5.- (a) Scheme of a "quasi-artificial leaf" based on a heterostructured $\mathrm{TiO}_{2} / \mathrm{PbS} / \mathrm{CdS}$ photoanode and $\mathrm{Pt}$ as cathode. (b) $\mathrm{The} \mathrm{TiO}_{2} / \mathrm{PbS} / \mathrm{CdS}$ "quasi-artificial leaf" in a quartz cuvette filled with an aqueous $0.25 \mathrm{M} \mathrm{Na}_{2} \mathrm{~S}$ and $0.35 \mathrm{M} \mathrm{Na}_{2} \mathrm{SO}_{3}$ electrolyte evolving $\mathrm{H}_{2}$ under illumination. A video of the $\mathrm{PbS}$ artificial leaf working autonomously is available in Supporting Information.

In summary, $\mathrm{TiO}_{2} / \mathrm{PbS} / \mathrm{CdS}$ heterostructures have demonstrated to be candidate architectures for solar hydrogen generation $\left(6 \mathrm{~mA} \cdot \mathrm{cm}^{-2}\right.$ or $60 \mathrm{ml} \cdot \mathrm{cm}^{-2} \cdot$ day $^{-1}$ obtained by cyclic voltammetry in a three electrode configuration under applied bias). Solar IR radiation provides a huge pool of photons, and consequently of usable energy, which can be stored using the appropriate materials, as PbS. Photocurrent and IPCE measurements have confirmed the contribution of infrared photons to the photocurrent leading to $\mathrm{H}_{2}$ generation. The integrated current perfectly agrees with that obtained by cyclic voltammetry, and an excellent spectral match between photocurrent and light harvesting has been obtained. Additionally, impedance spectroscopy appears as a simple and reliable characterization tool to inspect the limiting factors affecting the photoelectrochemical performance of the device. We showed that the recombination resistance $\left(\mathrm{R}_{\mathrm{rec}}\right)$ controls the dynamics of the system and further improvement of these heterostructures should be focused on strategies leading to the optimization of the $\mathrm{TiO}_{2}$ architecture and minimization of charge recombination. Furthermore, IS analysis suggests that transport and accumulation of charge in the film mainly takes place within the $\mathrm{TiO}_{2}$ nanoparticles. Based on this heterostructured material, we have developed a "quasi-artificial leaf", which has proven to produce autonomously hydrogen under simulated solar illumination at $(4.30 \pm 0.25) \mathrm{ml} \cdot \mathrm{cm}^{-}$ ${ }^{2}$. day $^{-1}$. Further developments at out lab focus on the elimination of the sacrificial agent in order 
to increase the robustness of the developed photoelectrodes. We believe that the present study constitutes an important milestone for the development of autonomous systems able to generate hydrogen with the only input of visible and IR radiation combining the advances of nanotechnology and novel optoelectronic concepts.

\section{Experimental method}

Commercial titania paste (Solarnix DSL 18NR, Switzerland, $20 \mathrm{~nm}$ particle size) was coated on FTO $\left(\mathrm{SnO}_{2}: \mathrm{F}\right.$, TEC 15) substrate by doctor blade technique and then dried at $80^{\circ} \mathrm{C}$. Prior to $\mathrm{TiO}_{2}$ nanoparticle deposition, the FTO substrates were covered by a compact layer of $\mathrm{TiO}_{2}$ deposited by spray pyrolisis of titanium(IV)bis(acetoacetonato) di(isopropanoxylate). These electrodes were subsequently sintered at $450{ }^{\circ} \mathrm{C}$ for $30 \mathrm{~min}$. The thickness of the electrodes was $\sim 12 \mu \mathrm{m}$, as measured by contact profilometry. The titania electrodes were sensitized with $\mathrm{PbS}$ QDs grown by Succesive Ionic Layer Adsorption and Reaction (SILAR). ${ }^{19}$ For this purpose a $\mathrm{Pb}\left(\mathrm{CH}_{3} \mathrm{COO}\right)_{2} 0.02 \mathrm{M}$ ethanolic solution was used as $\mathrm{Pb}^{2+}$ source and another one containing $\mathrm{Na}_{2} \mathrm{~S} 9 \mathrm{H}_{2} \mathrm{O} 0.02 \mathrm{M}$ in methanol/water $(50 / 50 \mathrm{~V} / \mathrm{V})$ as sulfide precursor. A single SILAR cycle consisted of 30 seconds dip-coating of the electrode into the lead precursor and then into the sulfide solution, also during 30 seconds. After each precursor bath, the photoanode was thoroughly rinsed by immersion in ethanol and dried. One cycle was sufficient for an adequate $\mathrm{PbS}$ sensitization.

For the hybrid $\mathrm{PbS} / \mathrm{CdS}$ samples, the $\mathrm{CdS}$ deposition was carried out immediately after $\mathrm{PbS}$ deposition. For CdS SILAR deposition a $\mathrm{Cd}\left(\mathrm{CH}_{3} \mathrm{COO}\right)_{2} 0.05 \mathrm{M}$ was used as metal precursor and $\mathrm{Na}_{2} \mathrm{~S} 9 \mathrm{H}_{2} \mathrm{O} 0.02 \mathrm{M}$ in methanol/water $(50 / 50 \mathrm{~V} / \mathrm{V})$ as sulfide precursor. SILAR procedure was repeated five times. $\mathrm{CdS}$ coating demonstrated to provide an effective protection of $\mathrm{PbS}$ from sulfide based electrolytes and an significant enhancement of the stability. After sensitization, all the samples have been coated with $\mathrm{ZnS}$, by dipping alternately into $0.1 \mathrm{M} \mathrm{Zn}\left(\mathrm{CH}_{3} \mathrm{COO}\right)_{2}$ (in water) and $0.1 \mathrm{M} \mathrm{Na}_{2} \mathrm{~S}$ solutions for $1 \mathrm{~min} / \mathrm{dip}$, rinsing with Milli-Q ultrapure water between dips ( 2 cycles). ${ }^{40}$ Reference "only CdS" samples have been produced, following the same steps described above, except the deposition of $\mathrm{PbS}$. 
Structural inspection of the samples was carried out using a JEOL JEM-3100F field emission scanning electron microscope (SEM) and a JEOL JSM 7600F field emission transmission electron microscope (TEM). The crystallographic structure of the samples was tested by X-ray diffraction (XRD). The optical density of the photoelectrodes were recorded between 300 and $800 \mathrm{~nm}$ by a Cary 500 UV-VIS Varian spectrophotometer.

The transmittance spectra of the photoelectrodes were recorded between 300 and $800 \mathrm{~nm}$ by a Cary 500 UV-VIS Varian spectrophotometer. Steady state and chopped light current density voltage $(\mathrm{j}-\mathrm{V})$, Electrochemical Impedance Spectroscopy (EIS) and $\mathrm{V}_{\mathrm{oc}}$ decay measurements were carried out using a FRA equipped PGSTAT-30 from Autolab. A three-electrode configuration was used, where the $\mathrm{TiO}_{2} / \mathrm{PbS} / \mathrm{CdS}$ photo-electrode was connected to the working electrode, a $\mathrm{Pt}$ wire was connected to the counterelectrode and a saturated $\mathrm{Ag} / \mathrm{AgCl}$ electrode was used as reference. An aqueous solution containing $0.25 \mathrm{M} \mathrm{Na}_{2} \mathrm{~S}$ and $0.35 \mathrm{M} \mathrm{Na}_{2} \mathrm{SO}_{3}$ as sacrificial hole scavenger was used as the electrolyte to prevent photocorrosion of the QDs. Nitrogen was bubbled during 30min before testing to avoid the presence of oxygen (electron acceptor) in the solution. The $\mathrm{pH}$ of the solution was 13 and all the electrochemical measurements were referred to the reversible hydrogen electrode (RHE) by the equation $V_{R H E}=V_{A g / A g C l}+0.197+p H(0.059)$. The electrodes were illuminated using a $450 \mathrm{~W}$ Xe lamp (Oriel), where the light intensity was adjusted with a thermopile to $100 \mathrm{~mW} / \mathrm{cm}^{2}$, with illumination through the substrate. EIS measurements were carried out applying $20 \mathrm{mV}$ AC signal and scanning in a frequency range between $400 \mathrm{kHz}$ and $0.1 \mathrm{~Hz}$, at different applied biases. The IPCE measurements were carried out by employing a $300 \mathrm{~W}$ Xe lamp coupled with a computer-controlled monochromator; the photoelectrode was polarized at the desired voltage with a Gamry potentiostat and the photocurrent was measured using an optical power meter 70310 from Oriel Instruments. Labeling experiments of the evolved gases were carried out using gas chromatography mass spectroscopy GC/MS. A quadrupole Pfeiffer Vacuum model Thermostar GSD301T with a mass interval ranging down to 300 uma was used. The evolved gas was collected in an inverted burette and extracted with a gas-tight syringe provided with an exit valve. The quantitative analysis of the evolved gas for the wireless device was carried out by collecting the generated gas under 100 $\mathrm{mW} \cdot \mathrm{cm}^{-2}$ illumination with an inverted burette during 1 hour. The obtained result was 
extrapolated to 1 day. During this measurement, no addition of fresh electrolyte to the solution was carried out.

\section{Acknowledgements}

We acknowledge support by projects from Ministerio de Economia y Competitividad (MINECO) of Spain (Consolider HOPE CSD2007-00007, MAT2010-19827), Generalitat Valenciana (PROMETEO/2009/058 and project ISIC/2012/008 "Institute of Nanotechnologies for Clean Energies") and Fundació Bancaixa (P1.1B2011-50). S. Gimenez acknowledges support by MINECO of Spain under the Ramon y Cajal programme. The SCIC of the University Jaume I de Castello is also acknowledged for the gas analysis measurements. C. Sima acknowledges the POSDRU/89/1.5/S/58852 Project, "Postdoctoral programme for training scientific researchers" cofinanced by the European Social Fund within the Sectorial Operational Program Human Resources Development 2007-2013. We want to acknowledge Prof. J. Bisquert for the fruitful discussions related with this manuscript.

Supporting Information Available: $\mathrm{TiO}_{2} / \mathrm{CdS}$ and $\mathrm{TiO}_{2} / \mathrm{PbS} / \mathrm{CdS}$ light absorption, $\mathrm{SEM}$ image, $\mathrm{XRD}$ of $\mathrm{TiO}_{2} / \mathrm{PbS}$ electrodes, TEM micrograph, stability, IPCE vs. light absorption and APCE, impedance model and a video of the PbS artificial leaf working autonomously. This material is available free of charge via the Internet at http://pubs.acs.org.

\section{References}

(1) Crabtree, G. W.; Lewis, S. N. Solar Energy Conversion. Physics Today. 2007, 60, 37-42.

(2) Walter, M. G.; Warren, E. L.; McKone, J. R.; Boettcher, S. W.; Mi, Q. X.; Santori, E. A.; Lewis, N. S. Solar Water Splitting Cells. Chem. Rev. (Washington, DC, U. S.). 2010, 110, 6446-6473.

(3) Cook, T. R.; Dogutan, D. K.; Reece, S. Y.; Surendranath, Y.; Teets, T. S.; Nocera, D. G. Solar Energy Supply and Storage for the Legacy and Non legacy Worlds. Chem. Rev. (Washington, DC, U. S.). 2010, 110, 6474-6502.

(4) van de Krol, R.; Liang, Y. Q.; Schoonman, J. Solar hydrogen production with nanostructured metal oxides. J. Mater. Chem. 2008, 18, 2311-2320.

(5) Fujishima, A.; Honda, K. Electrochemical Photolysis of Water at a Semiconductor Electrode. Nature. 1972, 238, 37-38. 
(6) Tilley, S. D.; Cornuz, M.; Sivula, K.; Gratzel, M. Light-Induced Water Splitting with Hematite: Improved Nanostructure and Iridium Oxide Catalysis. Angewandte Chemie-International Edition. 2010, 49, 6405-6408.

(7) Kelzenberg, M. D.; Boettcher, S. W.; Petykiewicz, J. A.; Turner-Evans, D. B.; Putnam, M. C.; Warren, E. L.; Spurgeon, J. M.; Briggs, R. M.; Lewis, N. S.; Atwater, H. A. Enhanced absorption and carrier collection in Si wire arrays for photovoltaic applications. Nat. Mater. 2010, 9, 239-244.

(8) Lin, Y. J.; Yuan, G. B.; Liu, R.; Zhou, S.; Sheehan, S. W.; Wang, D. W. Semiconductor nanostructurebased photoelectrochemical water splitting: A brief review. Chem. Phys. Lett. 2011, 507, 209215.

(9) Lin, Y. J.; Yuan, G. B.; Sheehan, S.; Zhou, S.; Wang, D. W. Hematite-based solar water splitting: challenges and opportunities. Energy \& Environmental Science. 2011, 4, 4862-4869.

(10) Holmes, M. A.; Townsend, T. K.; Osterloh, F. E. Quantum confinement controlled photocatalytic water splitting by suspended CdSe nanocrystals. Chem. Commun. (Cambridge, U. K.). 2012, 48, 371-373.

(11) Yang, S. Y.; Prendergast, D.; Neaton, J. B. Tuning Semiconductor Band Edge Energies for Solar Photocatalysis via Surface Ligand Passivation. Nano Lett. 2012, 12, 383-388.

(12) Thimsen, E.; Le Formal, F.; Gratzel, M.; Warren, S. C. Influence of Plasmonic Au Nanoparticles on the Photoactivity of $\mathrm{Fe}(2) \mathrm{O}(3)$ Electrodes for Water Splitting. Nano Lett. 2011, 11, 35-43.

(13) Thomann, I.; Pinaud, B. A.; Chen, Z. B.; Clemens, B. M.; Jaramillo, T. F.; Brongersma, M. L. Plasmon Enhanced Solar-to-Fuel Energy Conversion. Nano Lett. 2011, 11, 3440-3446.

(14) Hensel, J.; Wang, G. M.; Li, Y.; Zhang, J. Z. Synergistic Effect of CdSe Quantum Dot Sensitization and Nitrogen Doping of $\mathrm{TiO}(2)$ Nanostructures for Photoelectrochemical Solar Hydrogen Generation. Nano Lett. 2010, 10, 478-483.

(15) Chen, H. M.; Chen, C. K.; Chang, Y. C.; Tsai, C. W.; Liu, R. S.; Hu, S. F.; Chang, W. S.; Chen, K. H. Quantum Dot Monolayer Sensitized ZnO Nanowire-Array Photoelectrodes: True Efficiency for Water Splitting. Angewandte Chemie-International Edition. 2010, 49, 5966-5969.

(16) Kim, H.; Seol, M.; Lee, J.; Yong, K. Highly Efficient Photoelectrochemical Hydrogen Generation Using Hierarchical ZnO/WOx Nanowires Cosensitized with CdSe/CdS. J. Phys. Chem. C. 2011, $115,25429-25436$.

(17) Luo, J. S.; Karuturi, S. K.; Liu, L.; Su, L. T.; Tok, A. I. Y.; Fan, H. J. Homogeneous Photosensitization of Complex TiO2 Nanostructures for Efficient Solar Energy Conversion. Scientific Reports. 2012, 2.

(18) Jin-nouchi, Y.; Hattori, T.; Sumida, Y.; Fujishima, M.; Tada, H. PbS Quantum Dot-Sensitized Photoelectrochemical Cell for Hydrogen Production from Water under Illumination of Simulated Sunlight. ChemPhysChem. 2010, 11, 3592-3595.

(19) Braga, A.; Gimenez, S.; Concina, I.; Vomiero, A.; Mora-Sero, I. Panchromatic Sensitized Solar Cells Based on Metal Sulfide Quantum Dots Grown Directly on Nanostructured TiO2 Electrodes. J. Phys. Chem. Lett. 2011, 2, 454-460.

(20) Bisquert, J. Chemical capacitance of nanostructured semiconductors: its origin and significance for nanocomposite solar cells. Phys. Chem. Chem. Phys. 2003, 5, 5360-5364.

(21) Fabregat-Santiago, F.; Randriamahazaka, H.; Zaban, A.; Garcia-Canadas, J.; Garcia-Belmonte, G.; Bisquert, J. Chemical capacitance of nanoporous-nanocrystalline $\mathrm{TiO} 2$ in a room temperature ionic liquid. Phys. Chem. Chem. Phys. 2006, 8, 1827-1833.

(22) Guijarro, N.; Lana-Villarreal, T.; Mora-Sero, I.; Bisquert, J.; Gomez, R. CdSe Quantum DotSensitized TiO2 Electrodes: Effect of Quantum Dot Coverage and Mode of Attachment. J. Phys. Chem. C. 2009, 113, 4208-4214.

(23) Chouhan, N.; Yeh, C. L.; Hu, S. F.; Huang, J. H.; Tsai, C. W.; Liu, R. S.; Chang, W. S.; Chen, K. H. Array of CdSe QD-Sensitized ZnO Nanorods Serves as Photoanode for Water Splitting. J. Electrochem. Soc. 2010, 157, B1430-B1433. 
(24) Smotkin, E. S.; Cerveramarch, S.; Bard, A. J.; Campion, A.; Fox, M. A.; Mallouk, T.; Webber, S. E.; White, J. M. Bipolar CdSe/CoS semiconductor photoelectrode arrays for unassisted photolytic water splitting. J. Phys. Chem. 1987, 91, 6-8.

(25) Fabregat-Santiago, F.; Garcia-Belmonte, G.; Mora-Sero, I.; Bisquert, J. Characterization of nanostructured hybrid and organic solar cells by impedance spectroscopy. Phys. Chem. Chem. Phys. 2011, 13, 9083-9118.

(26) Haynes, W. M., Handbook of Chemistry and Physics 83th edition. (CRC Press, 2002).

(27) Salvador, P. Kinetic approach to the photocurrent transients in water photoelectrolysis at TiO2 electrodes. I. Analysis of the ratio of the instantaneous to steady-dtate photocurrent. J. Phys. Chem. 1985, 89, 3863-3869.

(28) Klahr, B. M.; Gimenez, S.; Fabregat-Santiago, F.; Bisquert, J.; Hamann, T. W. Electrochemical and Photoelectrochemical Investigation of Water Oxidation with Hematite Electrodes. Energy Environ. Sci. 2012, 5, 7626-7636.

(29) Le Formal, F.; Gratzel, M.; Sivula, K. Controlling Photoactivity in Ultrathin Hematite Films for Solar Water-Splitting. Adv. Funct. Mater. 2010, 20, 1099-1107.

(30) Rodenas, P.; Song, T.; Sudhagar, P.; Marzari, G.; Han, H.; Badía-Bou, L.; Gimenez, S.; FabregatSantiago, F.; Mora-Sero, I.; Bisquert, J. et al. Quantum dot based heterostructures for unassisted photoelectrochemical hydrogen generation. Advanced Energy Materials. 2012, In press. DOI: 10.1002/aenm.201200255.

(31) Gonzalez-Pedro, V.; Xu, X. Q.; Mora-Sero, I.; Bisquert, J. Modeling High-Efficiency Quantum Dot Sensitized Solar Cells. ACS Nano. 2010, 4, 5783-5790.

(32) Mora-Sero, I.; Gimenez, S.; Fabregat-Santiago, F.; Gomez, R.; Shen, Q.; Toyoda, T.; Bisquert, J. Recombination in Quantum Dot Sensitized Solar Cells. Acc. Chem. Res. 2009, 42, 1848-1857.

(33) Bisquert, J. Theory of the impedance of electron diffusion and recombination in a thin layer. J. Phys. Chem. B. 2002, 106, 325-333.

(34) Bisquert, J.; Cahen, D.; Hodes, G.; Ruhle, S.; Zaban, A. Physical chemical principles of photovoltaic conversion with nanoparticulate, mesoporous dye-sensitized solar cells. J. Phys. Chem. B. 2004, 108, 8106-8118.

(35) Nocera, D. G. The Artificial Leaf. Acc. Chem. Res. 2012, 45, 767-776.

(36) Reece, S. Y.; Hamel, J. A.; Sung, K.; Jarvi, T. D.; Esswein, A. J.; Pijpers, J. J. H.; Nocera, D. G. Wireless Solar Water Splitting Using Silicon-Based Semiconductors and Earth-Abundant Catalysts. Science. 2011, 334, 645-648.

(37) Samadpour, M.; Gimenez, S.; Iraji Zad, A.; Taghavinia, N.; Calvo, M.; Miguez, H.; Mora-Sero, I. Effect of the architecture of TiO2 and QDs deposition strategy on the photovoltaic performance of Quantum Dot Sensitized Solar Cells. Electrochim. Acta. 2012, 75, 139-147.

(38) Sudhagar, P.; Song, T.; Lee, D. H.; Mora-Seró, I.; Bisquert, J.; Laudenslager, M.; Sigmund, W. M.; Park, W. I.; Paik, U.; Kang, Y. S. High Open Circuit Voltage Quantum Dot Sensitized Solar Cells Manufactured with ZnO Nanowire Arrays and Si/ZnO Branched Hierarchical Structures. J. Phys. Chem. Lett. 2011, 2, 1984-1990.

(39) Tang, J.; Kemp, K. W.; Hoogland, S.; Jeong, K. S.; Liu, H.; Levina, L.; Furukawa, M.; Wang, X. H.; Debnath, R.; Cha, D. K. et al. Colloidal-quantum-dot photovoltaics using atomic-ligand passivation. Nat. Mater. 2011, 10, 765-771.

(40) Shen, Q.; Kobayashi, J.; Diguna, L. J.; Toyoda, T. Effect of ZnS coating on the photovoltaic properties of CdSe quantum dot-sensitized solar cells. J. Appl. Phys. 2008, 103. 


\section{Figure captions}

Figure 1.- (a) $\mathrm{j}-\mathrm{V}$ curves for the $\mathrm{TiO}_{2} / \mathrm{PbS} / \mathrm{CdS}$ heterostructure in the dark (dashed lines) and under illumination at $100 \mathrm{~mW} \cdot \mathrm{cm}^{-2}$ (solid lines) in three electrode configuration, $\mathrm{TiO}_{2} / \mathrm{CdS}$ is also included as a reference (b) Gas chromatography Mass Spectroscopy plot of the evolved gas for $\mathrm{TiO}_{2} / \mathrm{PbS} / \mathrm{CdS}$ heterostructure. The signal of $\mathrm{H}_{2}$ is clearly increased after gas is passed through the system.

Figure 2. Energy diagram illustrating the oxidation at $\mathrm{PbS} / \mathrm{CdS}$ QDs-sensitized $\mathrm{TiO}_{2}$ particulate anodes. Energy levels were adapted from. ${ }^{25,26}$ The arrows indicate the traffic of electrons and holes.

Figure 3.- (a) Chopped light (black) and constant (red) illumination j-V curves in two electrode configuration of the $\mathrm{TiO}_{2} / \mathrm{PbS} / \mathrm{CdS}$ heterostructured photoanode. (b) IPCE (solid lines) and integrated current (dashed lines) for $\mathrm{T} \mathrm{TiO}_{2} / \mathrm{PbS} / \mathrm{CdS}$ (red) and a reference $\mathrm{TiO}_{2} / \mathrm{CdS}$ (black) photoelectrode at $0.95 \mathrm{~V}$ vs RHE.

Figure 4.- Parameters extracted after fitting the impedance spectroscopy spectra of the heterostructured $\mathrm{TiO}_{2} / \mathrm{PbS} / \mathrm{CdS}$ photoanodes, using the model previously developed. ${ }^{30-32}$ (a) Transport resistance, $R_{t r}$, (b) Chemical capacitance $\left(C_{\mu}\right)$, (c) recombination resistance $\left(R_{\text {rec }}\right)$ as a function of potential both in the dark and (d) under illumination. The red lines in (c) and (d) represent the total resistance extracted from derivation of the $\mathrm{j}-\mathrm{V}$ curve, $R=\left(\frac{d j}{d V}\right)^{-1}$. Error bars assigned to the experimental points have been obtained from the fitting error.

Figure 5.- (a) Scheme of a "quasi-artificial leaf" based on a heterostructured $\mathrm{TiO}_{2} / \mathrm{PbS} / \mathrm{CdS}$ photoanode and $\mathrm{Pt}$ as cathode. (b) The $\mathrm{TiO}_{2} / \mathrm{PbS} / \mathrm{CdS}$ "quasi-artificial leaf" in a quartz cuvette filled with an aqueous $0.25 \mathrm{M} \mathrm{Na}_{2} \mathrm{~S}$ and $0.35 \mathrm{M} \mathrm{Na}_{2} \mathrm{SO}_{3}$ electrolyte evolving $\mathrm{H}_{2}$ under illumination. A video of the $\mathrm{PbS}$ artificial leaf working autonomously is available in Supporting Information, audiovisual material. 
4

5

6

7

8

9

10

11

12

13

14

15

16

17

18

19

20

21

22

23

24

25

26

27

28

29

30

31

32

33

34

35

36

37

38

39

40

41

42

43

44

45

46

47

48

49

50

51

52

53

54

55

56

57

58

59

60 


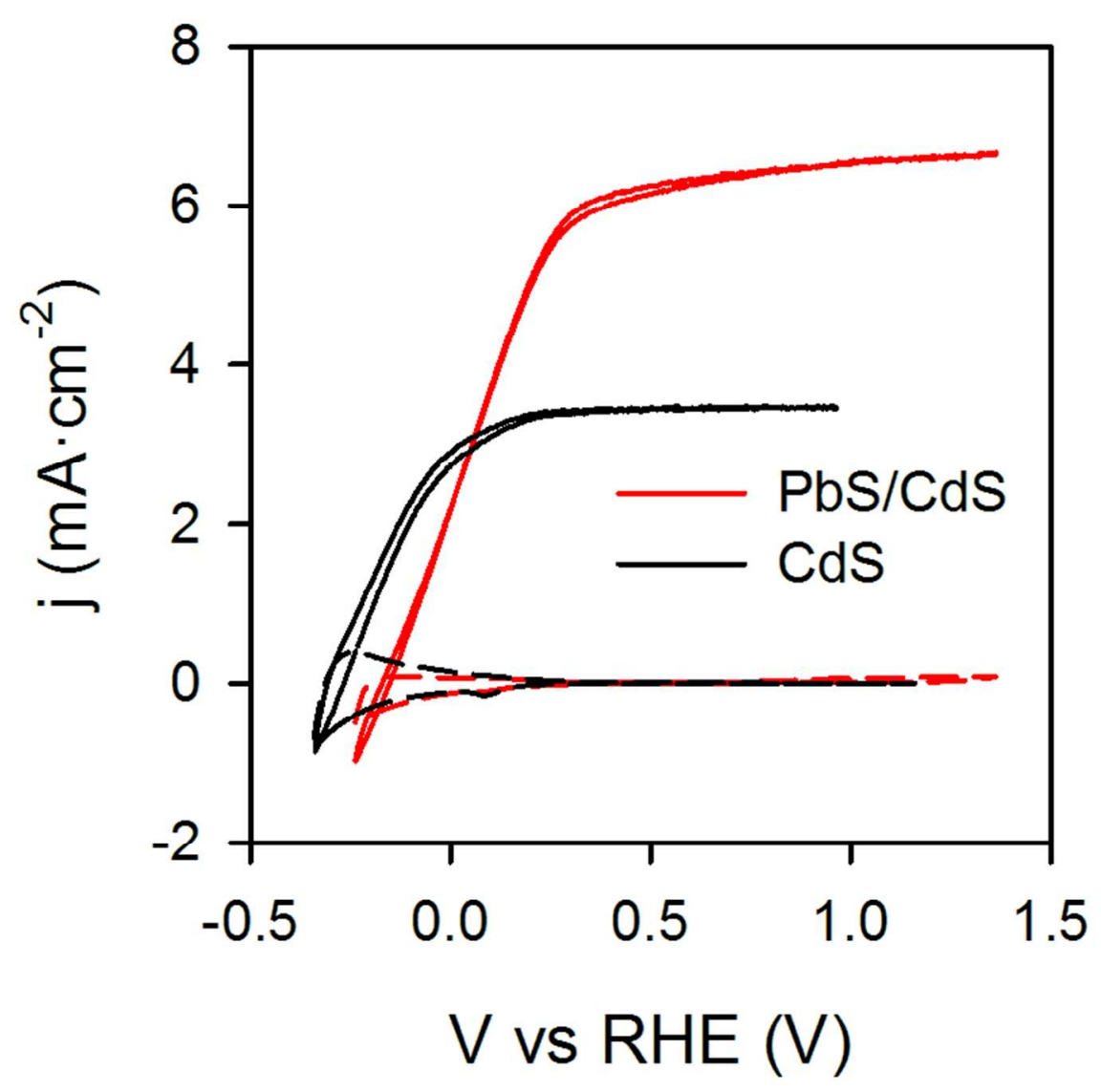

$77 \times 79 m m(300 \times 300$ DPI) 


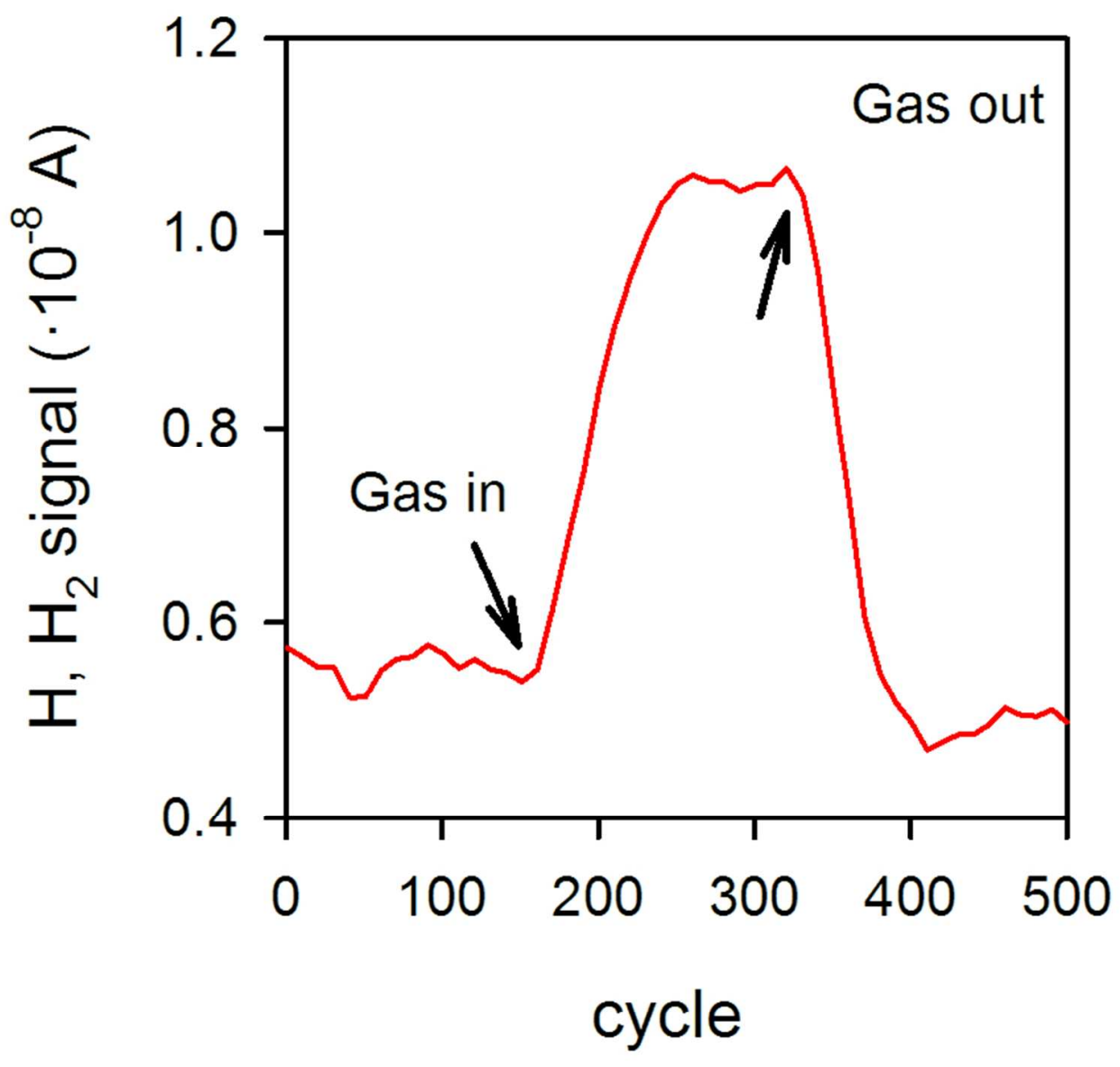

$75 \times 78 \mathrm{~mm}(300 \times 300$ DPI $)$ 


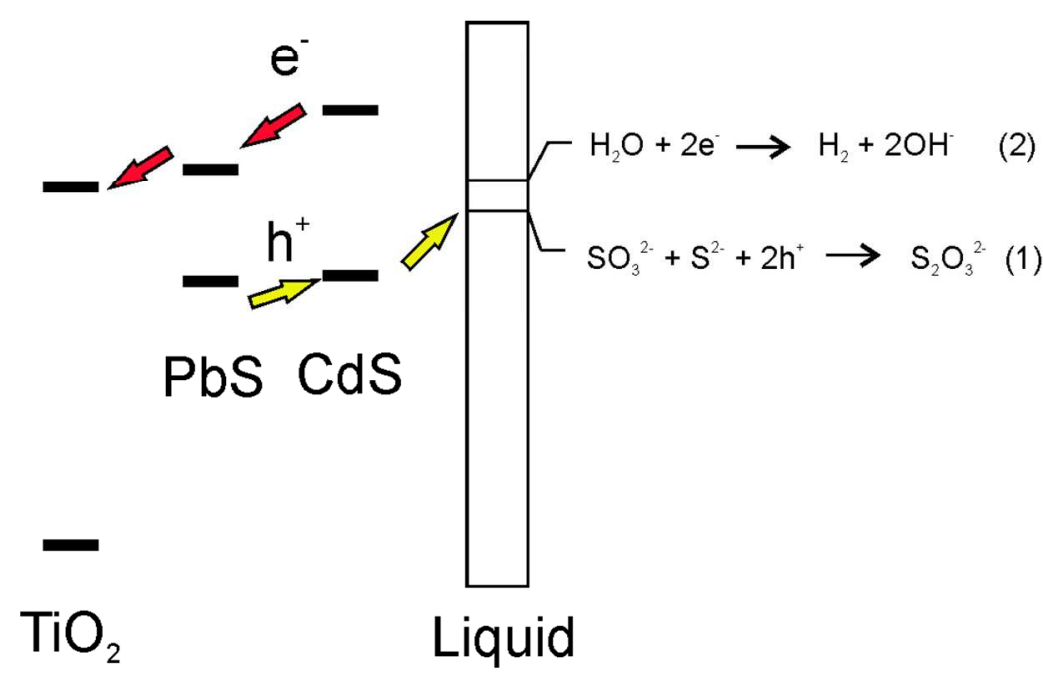

$116 \times 70 \mathrm{~mm}(300 \times 300 \mathrm{DPI})$ 


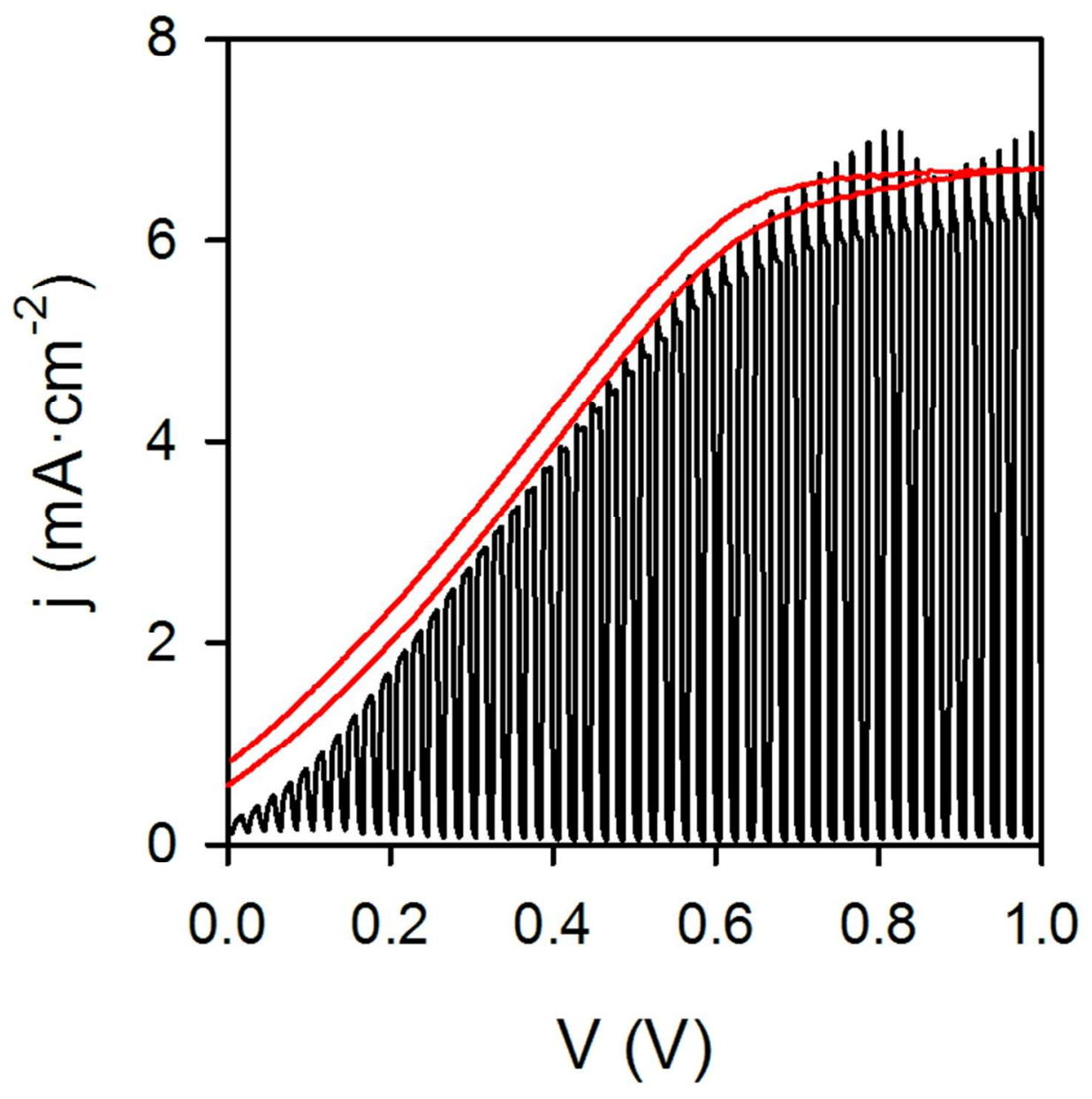

$71 \times 78 \mathrm{~mm}(300 \times 300$ DPI $)$ 


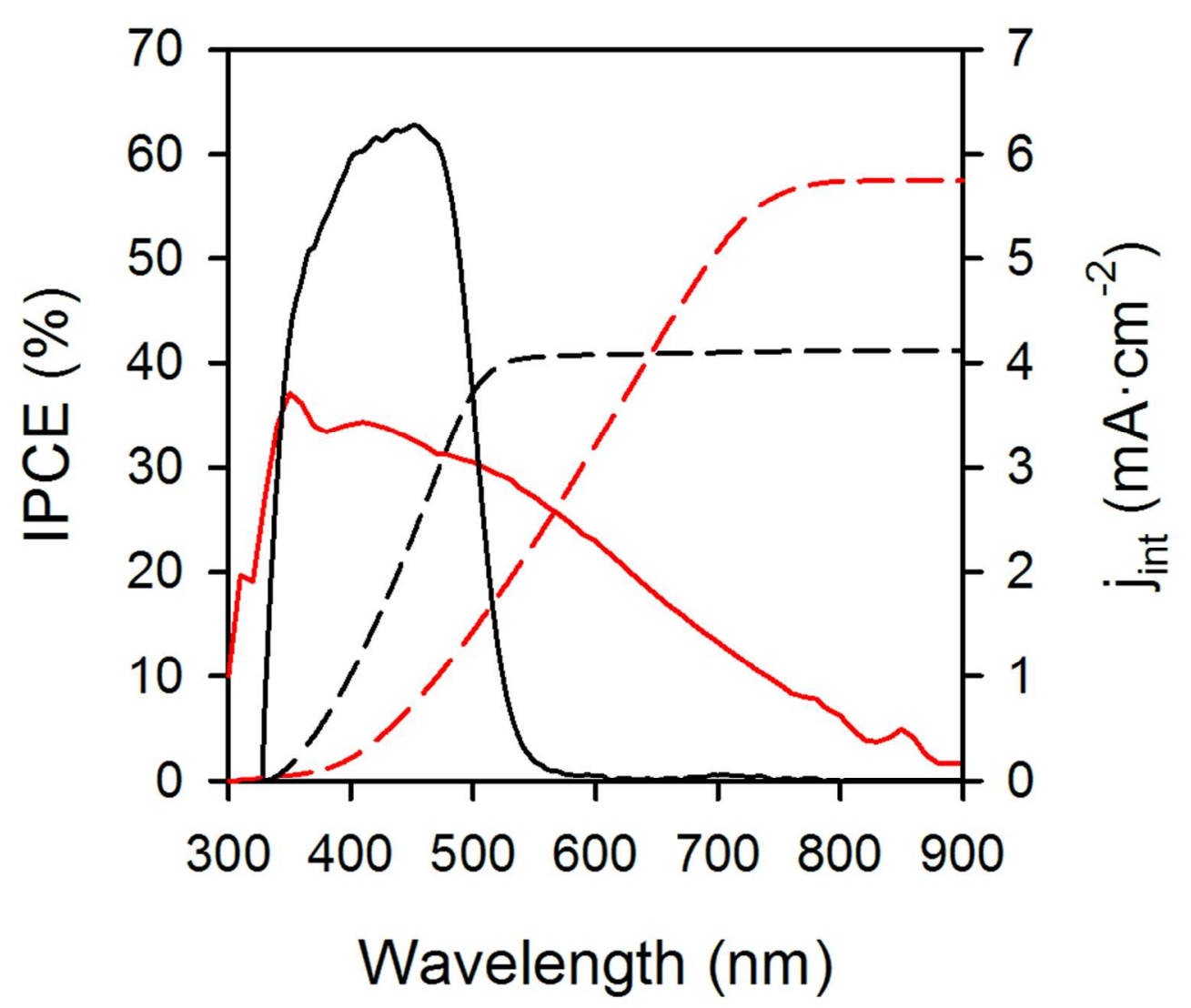

$80 \times 78 m m(300 \times 300$ DPI $)$ 


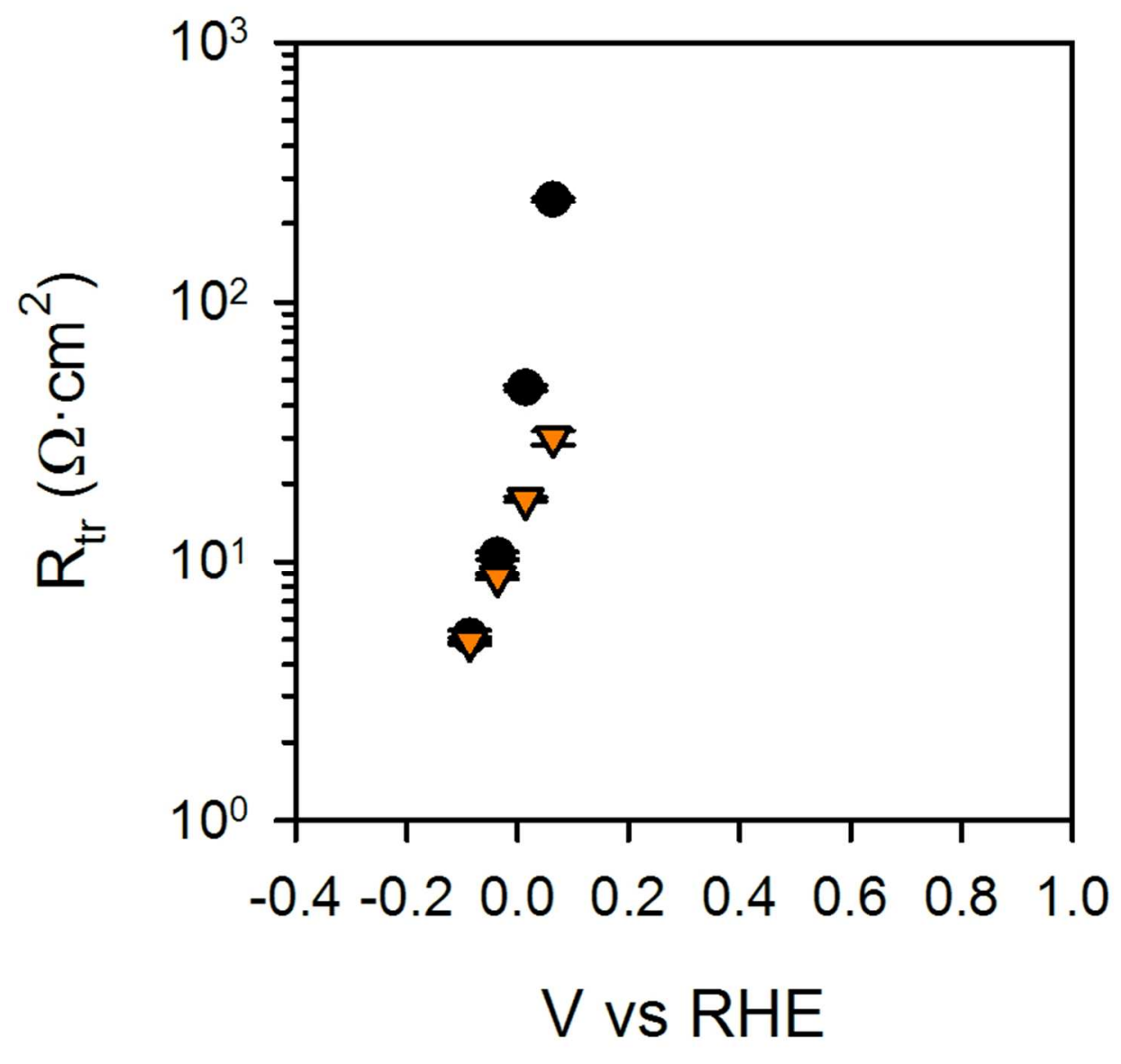

$75 \times 78 \mathrm{~mm}(300 \times 300 \mathrm{DPI})$ 


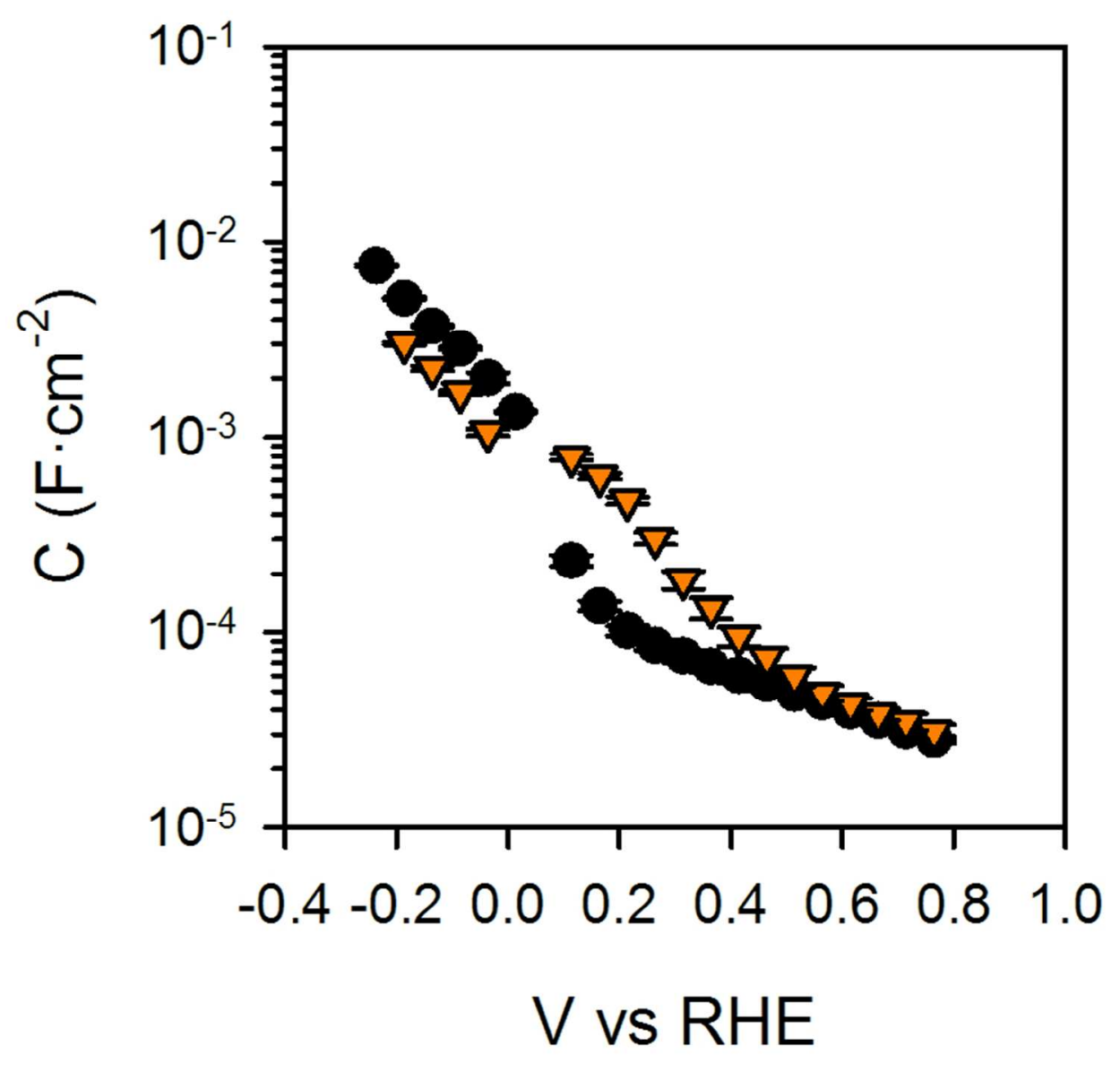

$74 \times 78 m m(300 \times 300$ DPI $)$ 


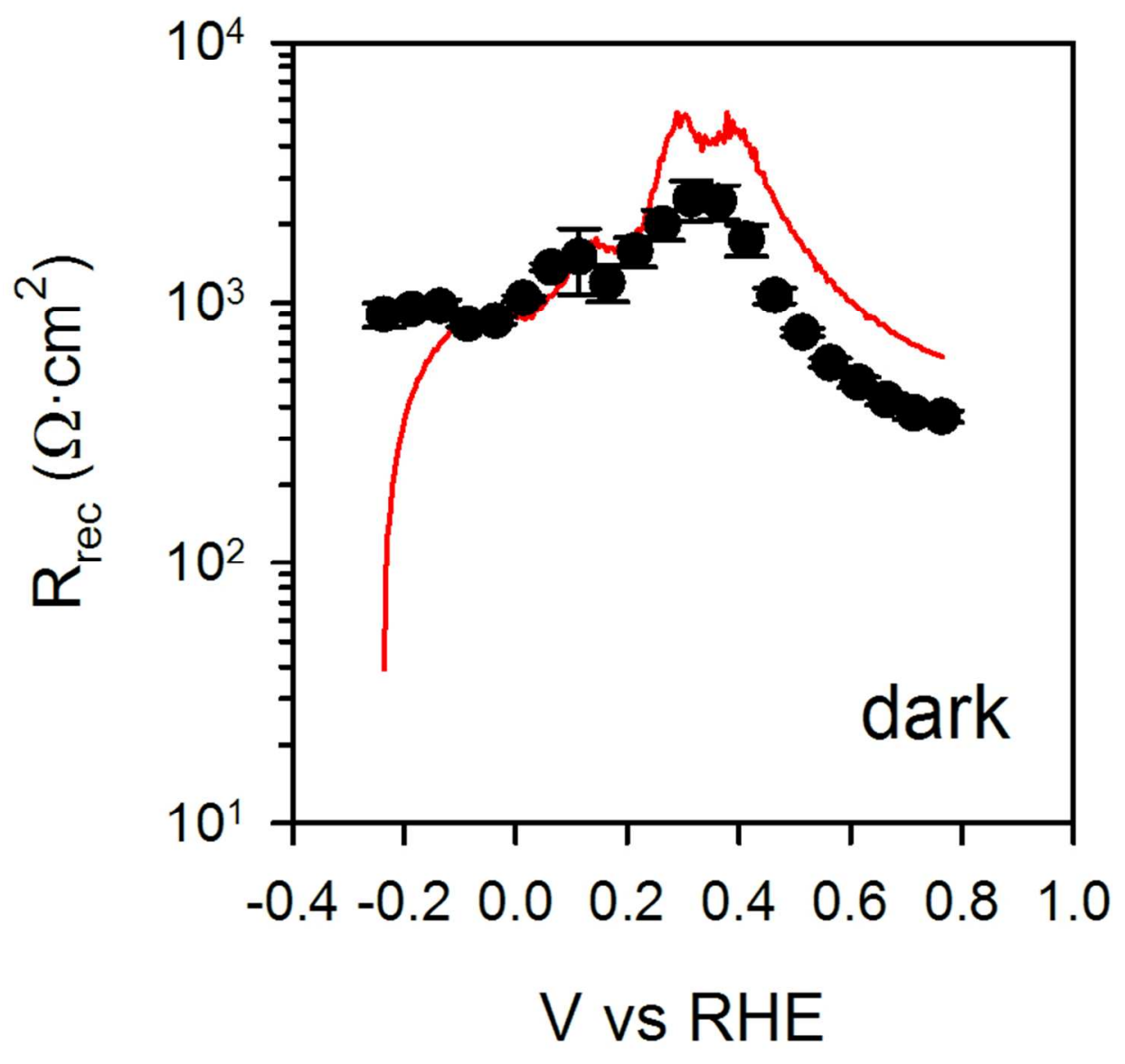

$75 \times 72 \mathrm{~mm}(300 \times 300 \mathrm{DPI})$ 


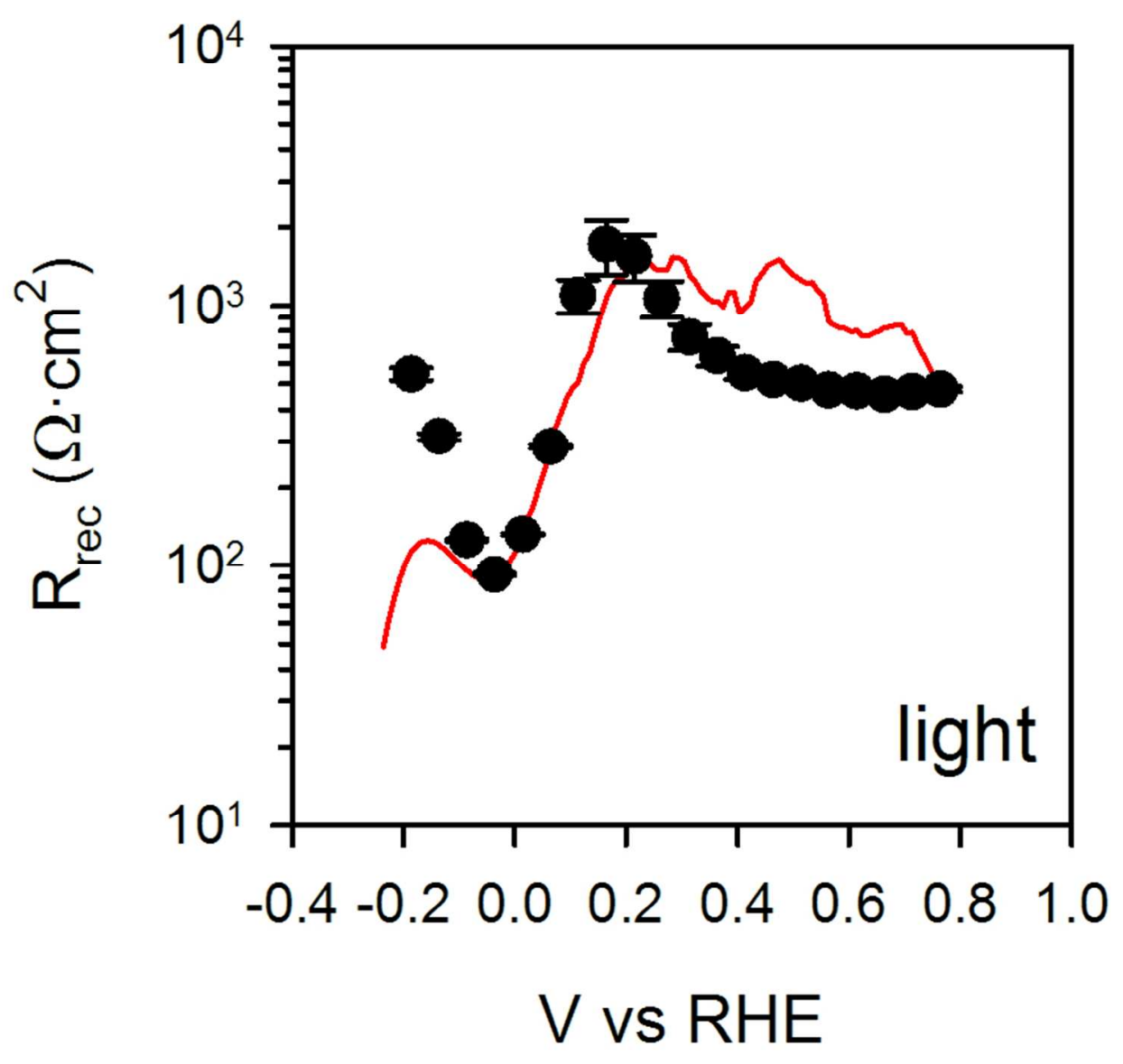

$75 \times 72 \mathrm{~mm}(300 \times 300$ DPI $)$ 


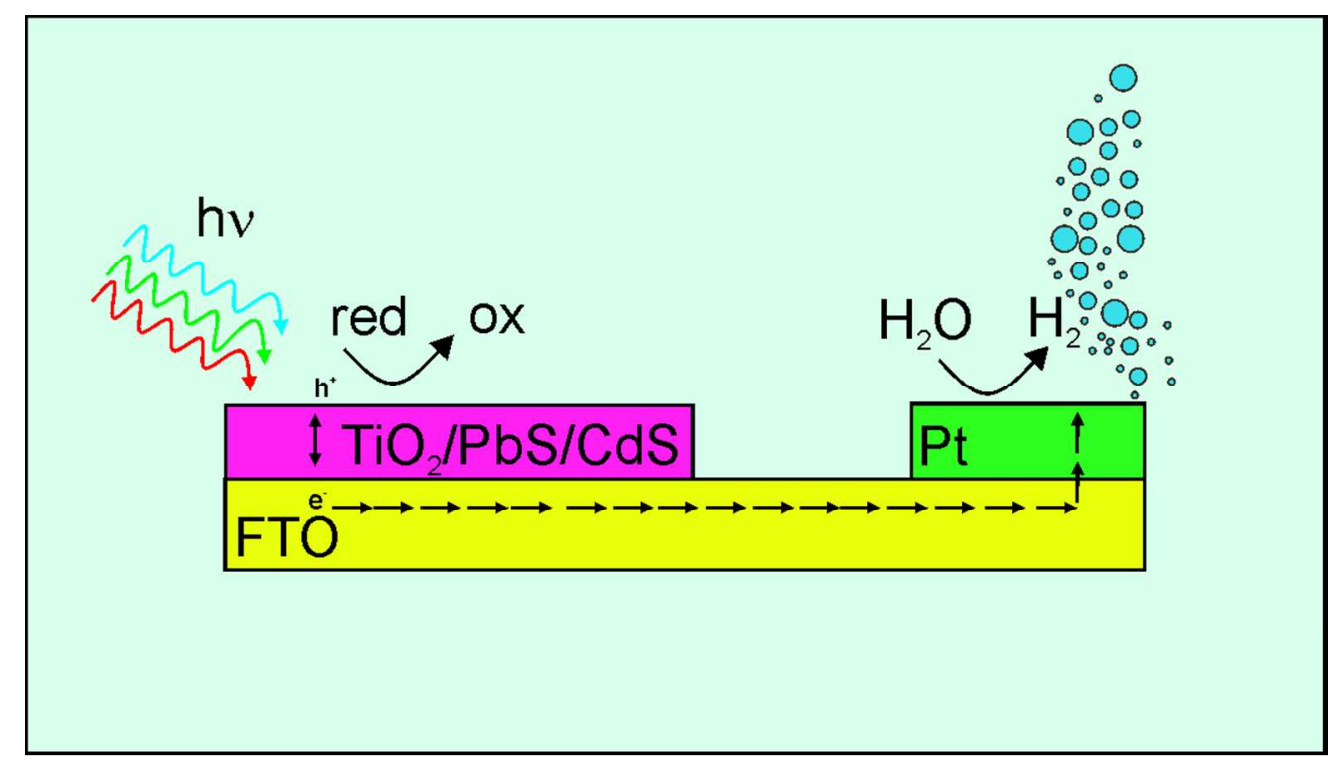

$101 \times 57 \mathrm{~mm}(300 \times 300 \mathrm{DPI})$ 


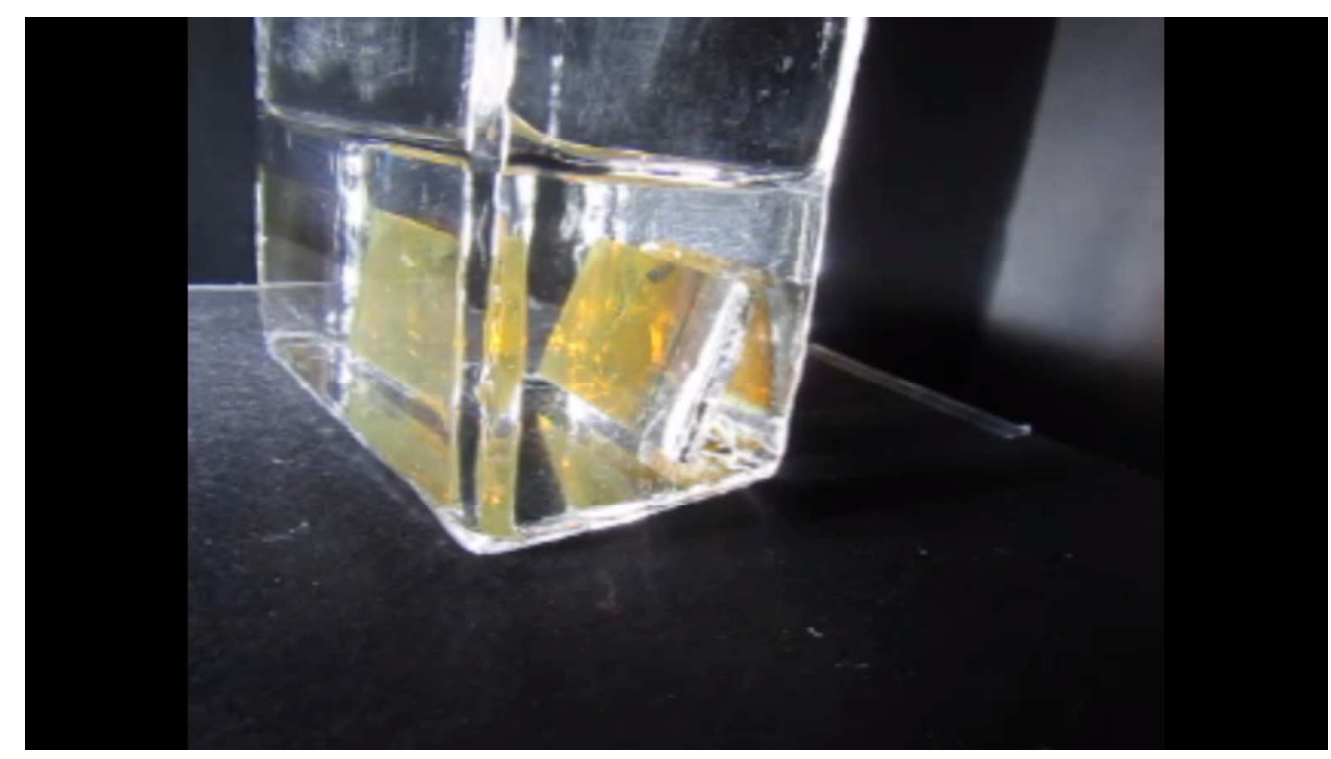



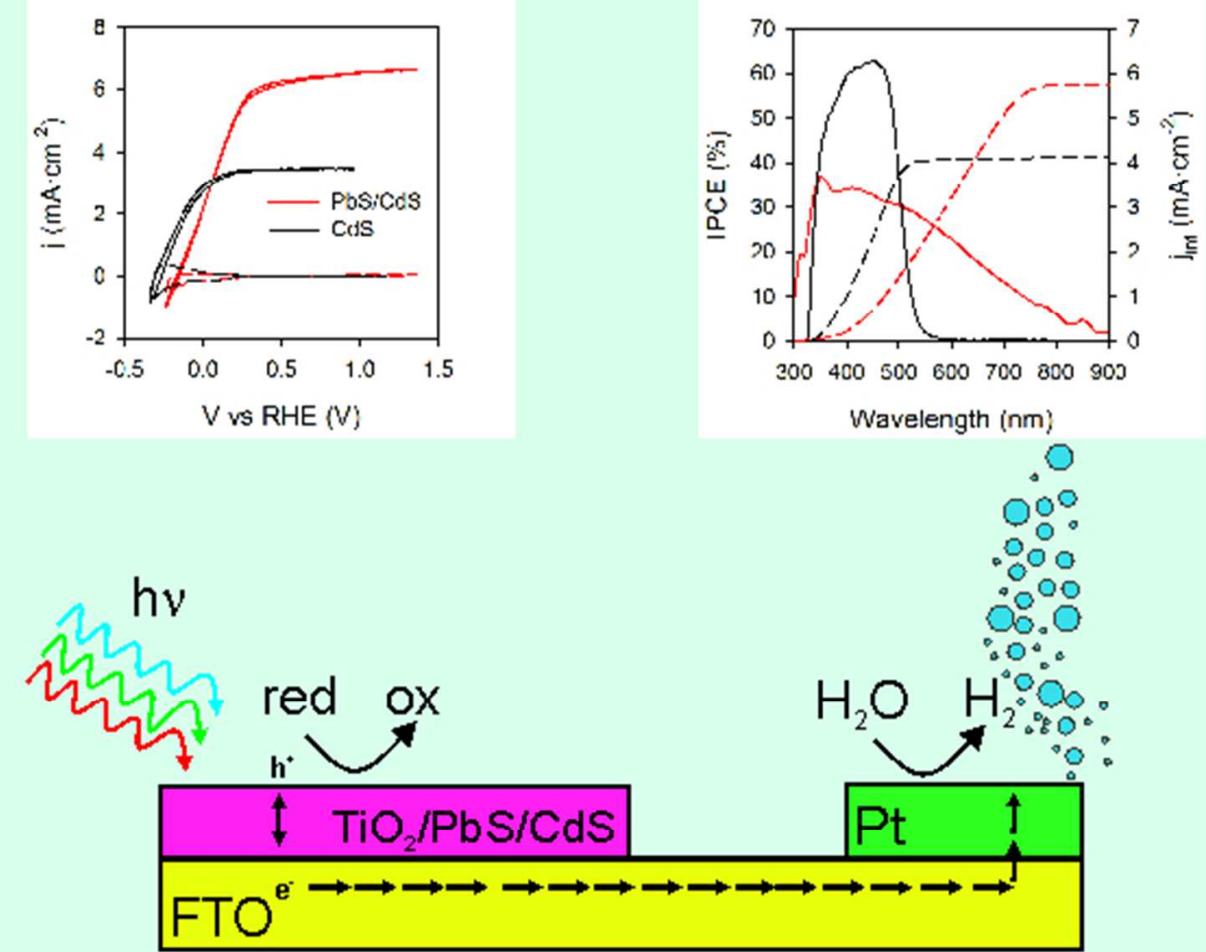

$50 \times 50 \mathrm{~mm}(300 \times 300 \mathrm{DPI})$ 